\title{
Review
}

\section{Review On Progress of 7xxx Series Aluminum Alloy Materials}

\author{
Yuxin Dai ${ }^{1}$, Liangming Yan ${ }^{1 *}$ and Jianpeng Hao ${ }^{1}$ \\ 1 College of Materials Science and Engineering, Inner Mongolia University of Technology, Hohhot Inner \\ Mongolia 010051,China. \\ * Correspondence: yanliangming@126.com; Tel.: +8613848106861
}

\begin{abstract}
Since the first generation of 7xxx superhard aluminum alloy was investigated in 1930, hitherto the fifth generation aluminum alloy materials with high comprehensive properties such as high static strength, high strength, heat resistance, high toughness, damage resistance, low density and low quenching sensitivity have been improved and developed. This paper reviews the progress of 7xxx aluminum alloy materials in composition, microstructure, properties, preparation methods, heat treatment strengthening and applications from 2014 to 2021. The effect of adding trace elements on microstructure and properties of 7xxx series alloy and the problems existing in aging precipitation characteristics and reinforcement mechanism are discussed. The future development direction of 7xxx superhard aluminum alloy is prospected by optimizing heat treatment technological, adding appropriate trace elements to alloy and controlling alloy microstructure.
\end{abstract}

Keywords: 7xxx superhard aluminum; Heat treatment technological; Alloy microstructure; Future direction

\section{Introduction}

7xxx series aluminum alloy can be strengthened by heat-treated and can achieve 490-820MPa, extensively used in industry and transportation trades[1]. According to the addition of elements are mainly classified into two categories: Al-Zn-Mg alloy has exhibited better weldability and general corrosion resistance, and high strength can be obtained when heat treatment is appropriate; the other is developed on the basis of $\mathrm{Al}-\mathrm{Zn}-\mathrm{Mg}$ alloy by adding $\mathrm{Cu}$, which has high specific strength, low density, yield strength close to tensile strength, exhibited better corrosion resistance and high toughness. It is the highest strength series of aluminum alloy and easy machinings, applied widely in large aircraft manufacturing and aerospace, and internationally recognized as the main aviation material[2-4]. In this paper, the new principle of process-microstructure-performance correlation is used to continuously improve the microstructure-performance characterization method of aluminum alloy based on the composition-process-microstructure-performance relationship of 7xxx series aluminum alloy, prospected future development direction of aluminum alloy.

\section{Element Alloying}

After adding $\mathrm{Zr}, \mathrm{Mn}, \mathrm{V}, \mathrm{Cr}$ and other microelement to 7xxx aluminum alloy, the hardness of the alloy decreases and the hardenability decreases in turn during slow quenching. In this section, the effects of four kinds of elements on the properties of 7xxx aluminum alloy are discussed respectively. Table 1 summarizes the related properties of 
alloyAl-Zn-Mg-Cu alloy.

Table.1 Summary of alloy elements on relevant properties of $\mathrm{Al}-\mathrm{Zn}-\mathrm{Mg}-\mathrm{Cu}[5]$

\begin{tabular}{|c|c|c|c|}
\hline Ele- & Precipitate & Content $(\omega \%)$ & Main effect \\
\hline \multirow[t]{2}{*}{$\mathrm{Zn}+\mathrm{Mg}$} & $\eta\left(\mathrm{MgZn}_{2}\right) ; \mathrm{T}\left(\mathrm{Al}_{2} \mathrm{Mg}_{2} \mathrm{Zn}_{3}\right)$ & $0.0-10 \quad(Z n \geqslant 0.9)$ & Increased tensile strength;heat treatment effect \\
\hline & & $\mathrm{Zn}+\mathrm{Mg} \geqslant 10 \%$ & $\begin{array}{l}\text { Decrease conductivity, fracture toughness, stress corrosion.resistance and spalling corrosion } \\
\text { resistance }\end{array}$ \\
\hline $\mathrm{Mg}$ & $\beta\left(\mathrm{Al}_{8} \mathrm{Mg}_{5}\right)$ & $0.0-4.0 \quad(\mathrm{Mg} \geqslant 0.0)$ & Reduce welding crack tendency \\
\hline $\mathrm{Mg}+\mathrm{C}$ & $\mathrm{S}\left(\mathrm{CuMgAl}_{2}\right)$ & $\mathrm{Zn} / \mathrm{Mg}>2.2 \quad \mathrm{Cu}>\mathrm{Mg}$ & Improve alloy strength \\
\hline \multirow[t]{2}{*}{$\mathrm{Cu}$} & $\theta\left(\mathrm{CuAl}_{2}\right)$ & $\leqslant 3$ & Improve corrosion resistance \\
\hline & & & $\begin{array}{l}\text { Expand the stable temperature range of GP zone, improve the tensile strength, plasticity and } \\
\text { fatigue strength }\end{array}$ \\
\hline \multirow[t]{2}{*}{$\mathrm{Cr}$} & Incoherent $\mathrm{E}\left(\mathrm{Al}_{18} \mathrm{Cr}_{2} \mathrm{Mg}_{3}\right)$ & $\leqslant 0.35$ & Nucleation and precipitation of coarse equilibrium phase \\
\hline & $\begin{array}{l}\mathrm{Cr}_{7} \mathrm{Al} 7 ;(\mathrm{CrMn}) \mathrm{Al}_{12} \\
(\mathrm{CrFe}) \mathrm{Al}_{7}\end{array}$ & $0.1-0.2$ & $\begin{array}{l}\text { Fine grain strengthening; inhibits recrystallization nucleation and growth;Improve anti SCC } \\
\text { ability }\end{array}$ \\
\hline \multirow[t]{2}{*}{$\mathrm{Mn}$} & $\mathrm{Al}_{6} \mathrm{Mn}$ & $0.2-0.4$ & $\begin{array}{l}\text { Improve maximum tensile strength and fracture toughness, performance of low cycle fa- } \\
\text { tigue,Quenching sensitivity }\end{array}$ \\
\hline & $\mathrm{Al}_{20} \mathrm{Cu}_{2} \mathrm{Mn}_{3}$ & $>0.4$ & Reduce the number of strengthening phases \\
\hline $\mathrm{Zr}$ & $\mathrm{Al}_{3} \mathrm{Zr}$ & $0.05-0.16$ & Improve the strength, toughness, aging effect and corrosion resistance of the alloy. \\
\hline $\mathrm{Ag}$ & & 0.16 & Promote the formation of GP region and transition phase;delay the over aging of the alloy. \\
\hline Co & $(\mathrm{Co}, \mathrm{Fe}) \mathrm{Al}_{9}, \mathrm{Co}_{2} \mathrm{Al} 9$ & $0.05 \leqslant \geqslant 0.2$ & Improve the hardenability;retention of subcrystalline structure \\
\hline $\mathrm{Ti}$ & & $0.01-0.08$ & Refine grain, improve casting properties \\
\hline Er & $\mathrm{Al}_{3} \mathrm{Er} ; \mathrm{Al}_{8} \mathrm{Cu} 4 \mathrm{Er}$ & $0.1-0.15$ & Improve the toughness; hardenability; dimples appear \\
\hline Sc & $\mathrm{Al}_{3} \mathrm{Sc}$ & $0.1-0.4$ & Grain refinement;recrystallization inhibition \\
\hline $\mathrm{Sc}+\mathrm{Zr}$ & $\mathrm{Al}_{3}(\mathrm{Sc}, \mathrm{Zr})$ & 0.6 & Improve anti SCC ability; \\
\hline Y & $\mathrm{Al}_{3} \mathrm{Y}$ & 0.3 & Improve the hardness, tensile strength, elongation \\
\hline
\end{tabular}




\begin{tabular}{llll}
\hline $\mathrm{Gd}$ & $\mathrm{Al}_{3}(\mathrm{Gd}, \mathrm{Zr})$ & 0.11 & Hindering dislocation ;grain boundary movement \\
$\mathrm{Si}$ & $\mathrm{Mg}_{2} \mathrm{Si} ; \mathrm{AlFeMnSi}$ & $\geqslant 0.15$ & Reduce plasticity and fracture toughness \\
$\mathrm{Fe}$ & $\mathrm{Al}_{6} \mathrm{FeMn}$ & $\geqslant 0.15$ & Reduce plasticity and fracture toughness \\
\hline
\end{tabular}

\subsection{Main Alloy Elements}

In $\mathrm{Al}-\mathrm{Zn}-\mathrm{Mg}$ alloy, $\mathrm{Zn}$ and $\mathrm{Mg}$ are the main alloy elements not more than $7.5 \%$. With the increase of $\mathrm{Zn}$ and $\mathrm{Mg}$ content, the ultimate tensile strength and heat treatment effect improved. When the content of $\mathrm{Mg}+\mathrm{Cu} \leq 7 \%$, the alloy has exhibit better stress corrosion resistance and the welding crack tendency decreases with the increase of $\mathrm{Mg}$. The main function of $\mathrm{Cu}$ element in $\mathrm{Al}-\mathrm{Zn}-\mathrm{Mg}$ - $\mathrm{Cu}$ alloy is to improve the corrosion resistance of the material, and $\mathrm{Cu}$ element also has a certain enhancement effect[6]. $\mathrm{Zn}$ and $\mathrm{Mg}$ will form $\eta(\mathrm{MgZn} 2)$ phase and $\mathrm{T}\left(\mathrm{Al}_{2} \mathrm{Mg}_{2} \mathrm{Zn} 3\right)$ phase after co-existence and aging. $\mathrm{Mg} / \mathrm{Zn}$ mass ratio in the range of 5:2-7:1 can refine the precipitates and improve the strength of the alloy; when the content of $\mathrm{Zn}+\mathrm{Mg} \geq 10 \%$, the electrical conductivity, fracture toughness, stress corrosion resistance and exfoliation corrosion resistance of the alloy begin to decrease [7].

When the content of $\mathrm{Zn} / \mathrm{Mg}>2.2$ and $\mathrm{Cu}>\mathrm{Mg}$, the strengthening phase $\mathrm{S}\left(\mathrm{CuMgAl}_{2}\right)$ can enhance the strength of the alloy. The increase of $\mathrm{Cu}$ content will promote the recrystallization of the alloy, increase the density of the precipitated phase, and reduce the potential difference between the grain boundary and the grain[8]. The effect on PFZ (precipitation free zone) width is small, and the stress corrosion resistance of the alloy is improved. If the element ratio is not within this range, $S$ phase is the brittle phase that destroys the properties of the alloy. The size difference between $\mathrm{Cu}$ ato $\mathrm{bm}$ and $\mathrm{Al}$ atom quite distant, wherefore, the crystal lattice deformation of $\mathrm{Cu}$ dissolved in Al-based solid solution in the form of replacement solid solution will reduce the hardenability of aluminum alloy and promote the precipitation of second phase in quenching [9]. In the process, the aging strengthening effect is reduced, and the quenching sensitivity of the alloy is reduced. The artificial aging process of the alloy at $100^{\circ} \mathrm{C}-200^{\circ} \mathrm{C}$ is accelerated, expand the stable temperature range of the GP ( pre-dissolved atomic segregation area ) region and improve the ultimate tensile strength, plasticity and fatigue strength. However, the addition of $\mathrm{Cu}$ tends to produce intercrystalline corrosion and pitting corrosion. The commonly used chemical composition of 7xxx series aluminum alloys is shown in Table 2 [10]. In addition to the main alloy elements such as $\mathrm{Zn}, \mathrm{Mg}$ and $\mathrm{Cu}$, there are also minor $\mathrm{Mn}$ and $\mathrm{Cr}$ elements that not just form new strengthening phases with the main alloy elements to increase the alloy strength, simultaneously improve the thermal strength and corrosion resistance. 


\begin{tabular}{|c|c|c|c|c|c|c|c|c|c|c|c|c|}
\hline \multirow[t]{2}{*}{ Allloys } & \multirow[t]{2}{*}{$\mathrm{Si}$} & \multirow[t]{2}{*}{$\mathrm{Fe}$} & \multirow[t]{2}{*}{$\mathrm{Cu}$} & \multirow[t]{2}{*}{$\mathrm{Mn}$} & \multirow[t]{2}{*}{$\mathrm{Mg}$} & \multirow[t]{2}{*}{$\mathrm{Cr}$} & \multirow[t]{2}{*}{$\mathrm{Zn}$} & \multirow[t]{2}{*}{$\mathrm{Ti}$} & \multirow[t]{2}{*}{$\mathrm{Zr}$} & \multicolumn{2}{|c|}{ Other } & \multirow[t]{2}{*}{$\mathrm{Al}$} \\
\hline & & & & & & & & & & Each & Total & \\
\hline 7A01 & 0.30 & 0.30 & 0.01 & - & - & - & $0.9-1.3$ & - & - & 0.03 & - & Bal. \\
\hline 7A03 & 0.20 & 0.20 & $1.8-2.4$ & 0.10 & $1.2-1.6$ & 0.05 & $6.0-6.7$ & $0.02-0.08$ & - & 0.05 & 0.10 & Bal. \\
\hline 7A04 & 0.50 & 0.50 & $1.4-2.0$ & $0.20-0.60$ & $1.8-2.8$ & $0.10-0.25$ & $5.0-7.0$ & 0.10 & - & 0.05 & 0.10 & Bal. \\
\hline 7A05 & 0.25 & 0.25 & 0.20 & $0.15-0.40$ & $1.1-1.7$ & $0.05-0.15$ & $4.4-5.0$ & $0.02-0.06$ & $0.10-0.25$ & 0.05 & 0.15 & Bal. \\
\hline 7A09 & 0.50 & 0.50 & $1.2-2.0$ & 0.15 & $2.0-3.0$ & $0.16-0.30$ & $5.1-6.1$ & 0.10 & - & 0.05 & 0.10 & Bal. \\
\hline 7A10 & 0.30 & 0.30 & $0.50-1.0$ & $0.20-0.35$ & $3.0-4.0$ & $0.10-0.30$ & $3.2-4.2$ & 0.10 & - & 0.05 & 0.10 & Bal. \\
\hline 7A19 & 0.30 & 0.40 & $0.08-0.30$ & $0.30-0.50$ & $1.3-1.9$ & $0.10-0.20$ & $1.5-5.3$ & - & $0.08-0.20$ & 0.05 & 0.15 & Bal. \\
\hline 7А33 & 0.25 & 0.30 & $0.25-0.55$ & 0.05 & $2.2-2.7$ & $0.10-0.20$ & $4.6-5.4$ & 0.05 & - & 0.05 & 0.10 & Bal. \\
\hline 7A52 & 0.25 & 0.30 & $0.05-0.20$ & $0.20-0.50$ & $2.0-2.8$ & $0.15-0.25$ & $4.0-4.8$ & $0.05-0.18$ & $0.05-0.15$ & 0.05 & 0.15 & Bal. \\
\hline 7003 & 0.30 & 0.35 & 0.20 & 0.30 & $\begin{array}{l}0.50-1 . \\
0\end{array}$ & 0.20 & $5.0-6.5$ & 0.20 & $0.05-0.25$ & 0.05 & 0.15 & Bal. \\
\hline 7020 & 0.35 & 0.20 & 0.20 & $0.05-0.50$ & $1.0-1.4$ & $0.10-0.35$ & $4.0-5.0$ & - & $0.08-0.20$ & 0.05 & 0.15 & Bal. \\
\hline 7022 & 0.50 & 0.50 & $0.50-1.0$ & $0.10-0.40$ & - & $0.10-0.30$ & $4.3-5.2$ & - & - & 0.05 & 0.15 & Bal. \\
\hline 7050 & 0.12 & 0.15 & $2.0-2.6$ & 0.10 & $1.9-2.6$ & 0.04 & $5.7-6.7$ & 0.06 & $0.08-0.15$ & 0.05 & 0.15 & Bal. \\
\hline 7075 & 0.40 & 0.50 & $1.2-2.0$ & 0.03 & $2.1-2.9$ & $0.18-0.28$ & $5.1-6.1$ & 0.02 & - & 0.05 & 0.15 & Bal. \\
\hline 7475 & 0.10 & 0.12 & $1.2-1.9$ & 0.06 & $1.9-2.6$ & $0.18-0.25$ & $5.2-6.2$ & 0.06 & - & 0.05 & 0.15 & Bal. \\
\hline
\end{tabular}

Table.2 7xxx aluminum alloy grade and main chemical composition (w\% ) [12]

\subsection{Microalloying Elements}

Adding microcontent of $\mathrm{Zr}, \mathrm{Mn}, \mathrm{Cr}$, Ag elements in 7xxx series aluminum alloy can not only improve the recrystallization temperature of the alloy, but also refined crystal grain, thus make the alloy has high mechanical properties and anti-corrosion capacity.

\subsection{1 $\mathrm{Zr}$ and $\mathrm{Mn}$ Transition Elements}

Fang et al [11]. found that the addition of $\mathrm{Zr}(0.1 \% \sim 0.15 \%)$ in $7 x x x$ series aluminum alloy can form $\mathrm{Al}_{3} \mathrm{Zr}$ dispersion phase with significant strengthening effect on the alloy. The pinning effect of $\mathrm{Al}_{3} \mathrm{Zr}$ on grain boundary can inhibit the recrystallization and grain growth behavior of the alloy, and improve the yield strength, tensile strength and elongation of the alloy. Due to the extremely low solubility of $\mathrm{Zr}$ in aluminum, $\mathrm{Al}_{3} \mathrm{Zr}$ particles are easily precipitated with the addition of microcrystalline $\mathrm{Zr}$ element. It is concluded that $\mathrm{Al}_{3} \mathrm{Zr}$ is a small particle dispersed in the grain and on the crystal boundaries, which is beneficial to refine the alloy grain, improve the strength, toughness, aging effect and corrosion resistance of the alloy.

There are only three ways of Zr existence in aluminum alloy[12]: (1) Solid solution in the matrix; (2) In the process of solid solution or homogenization, coherent or incoherent $\mathrm{Al}_{3} \mathrm{Zr}\left(\mathrm{DO}_{23}\right)$ dispersion particles are release from the supersaturated solid solution, which acts as dispersion strengthening ; (3) During the melting process, Zr element segregated from the matrix, resulting in the formation of $\mathrm{Al}_{3} \mathrm{Zr}$ primary crystals with coarse size, which is not conducive to the alloy performance. 
Md Shahnewaz et al [13]. found that the addition of Mn in 7xxx series aluminum alloy forms $\mathrm{Al}_{6} \mathrm{Mn}$ particles, improves the stress corrosion resistance of the alloy. $\mathrm{Al}_{6} \mathrm{Mn}$ does not affect the width of PFZ and can increase the maximum tensile strength, fracture toughness, simultaneously improve the low cyclic fatigue performance. SH I et al .[14] pointed out that excessive $\mathrm{Mn}$ content would lead to the emergence of $\mathrm{Al}_{20} \mathrm{Cu}_{2} \mathrm{Mn}_{3}$ and other second-phase compounds in aluminum alloys, which reduced the number of strengthening elements and strengthening phases in aluminum alloys, and the quenching sensitivity increased with the excess height Mn content.

\subsection{2 $\mathrm{Cr}$ and $\mathrm{Ag}$ Microalloying Elements}

7xxx aluminum alloy has strong quenching sensitivity, and it is difficult to prepare rather thick plates with consistent strength [4,15]. If $\mathrm{Zr}$ is substituted by $\mathrm{Cr}$, the quenching sensitivity can be greatly reduced and the effect of $\mathrm{Cr}$ on inhibiting recrystallization of 7xxx aluminum alloy can be retained.Many investigations have shown that [11,16-18]: $\mathrm{Cr}$ element can form fine second phases of intermetallic compounds such as $\mathrm{Cr}_{7} \mathrm{Al}_{7}$, $(\mathrm{CrMn}) \mathrm{Al}_{12}$ and $(\mathrm{CrFe}) \mathrm{Al}_{7}$ in aluminum alloy, which can effectively prevent the recrystallization nucleation and growth of aluminum alloy during processing. Microamount of $\mathrm{Cr}$ will improve the stress corrosion resistance of aluminum alloy, and its combination with $\mathrm{Cu}$ will be better. Generally, the content of $\mathrm{Cr}$ in aluminum alloy is 0.1-0.2 \%. However, in recent years, due to the better comprehensive performance of dispersion particles generated by $\mathrm{Zr}$ and other elements or aluminum matrix, $\mathrm{Zr}$ is used to replace Cr.

Feng et al.[19] added minor $\mathrm{Ag}(0.16 \%)$ to $\mathrm{Al}-\mathrm{Zn}-\mathrm{Mg}-\mathrm{Cu}-\mathrm{Zr}$ alloy, and discoved that Ag could promote the formation of GP zone and transition phase, improve the stability of transition phase, delay the overaging of alloy, and thus improve the thermal stability of aluminum alloy[20]. Figure 1 XRD shows that the addition of Ag element in 7xxx series aluminum alloy does not change the main phase composition.

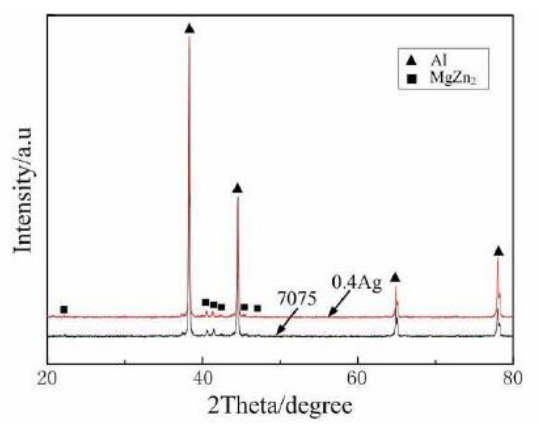

Figure. $1 \mathrm{XRD}$ pattern of as-cast $7075(0 \mathrm{Ag})$ alloy and $0.4 \mathrm{Ag}$ alloy[20]

Figure2 is the rolled structure of the alloy with different content of Ag element. After homogenization treatment and rolling deformation of 7075 alloy, it can be identified the grains become longer along the rolling direction. After homogenization treatment, there are still superior second phases around the grains. The second phase of the alloy containing $\mathrm{Ag}$ is less than that of the alloy without $\mathrm{Ag}$, and the aggregation phenomenon is weakened. 


\begin{tabular}{|c|c|c|c|c|c|c|c|}
\hline Element & $\mathrm{HV}$ & $\begin{array}{c}\text { Atomic } \\
\text { radius(nm) }\end{array}$ & $\begin{array}{l}\text { Relative } \\
\text { difference } \\
\text { with Al } \\
\text { atomic } \\
\text { radius }(\%)\end{array}$ & Electronegativity & $\begin{array}{l}\text { Electronegativity } \\
\text { difference with } \\
\text { Al }\end{array}$ & $\begin{array}{l}\text { Melting point } \\
\text { of pure alumi- } \\
\text { num and eu- } \\
\text { tectic tempera- } \\
\text { ture difference } \\
\left({ }^{\circ} \mathrm{C}\right)\end{array}$ & $\begin{array}{l}\text { Eutectic point } \\
\text { composition } \\
(w(\mathrm{RE}) \%)\end{array}$ \\
\hline Er & 700 & 0.1757 & 23 & 1.2 & 0.3 & 5 & 1 \\
\hline Sc & 850 & 0.1641 & 14.8 & 1.3 & 0.2 & 5 & 0.3 \\
\hline Y & 600 & 0.1803 & 26.2 & 1.2 & 0.3 & 10 & 3.3 \\
\hline $\mathrm{La}$ & 400 & 0.1877 & 31.4 & 1.1 & 0.4 & 20 & 2.5 \\
\hline $\mathrm{Ce}$ & 250 & 0.1824 & 27.6 & 1.05 & 0.45 & 20 & 2 \\
\hline $\mathrm{Nd}$ & 350 & 0.1522 & 27.5 & 1.2 & 0.3 & 20 & 7.4 \\
\hline $\mathrm{Sm}$ & 450 & 0.1802 & 26.1 & 1.2 & 0.3 & 28 & 1.5 \\
\hline $\mathrm{Eu}$ & - & 0.2041 & 42.8 & 1.1 & 0.4 & - & - \\
\hline $\mathrm{Gd}$ & 550 & 0.1801 & 26 & 1.2 & 0.3 & 17 & 2 \\
\hline $\mathrm{Tb}$ & 600 & 0.1783 & 24.8 & 1.2 & 0.3 & 16 & 1.8 \\
\hline Dy & 550 & 0.1775 & 24.2 & 1.2 & 0.3 & 24 & 8.2 \\
\hline Ho & 600 & 0.1767 & 23.7 & 1.2 & 0.3 & 13 & 2.6 \\
\hline $\mathrm{Tm}$ & 650 & 0.1747 & 22.3 & 1.2 & 0.3 & 16 & 1.7 \\
\hline $\mathrm{Yb}$ & 250 & 0.1939 & 35.7 & 1.1 & 0.4 & 35 & 4 \\
\hline
\end{tabular}

It can be discern from Table 3 that the difference between the melting point of pure aluminum and the eutectic temperatures of rare earth elements Er and Sc is relatively low and the eutectic point composition of Sc is the lowest, $\mathrm{w}(\mathrm{Sc}) \% \approx 0.3 \%, \mathrm{w}(\mathrm{Er}) \approx 1.0 \%$. Therefore, it can be perceived that the properties of 7xxx aluminum alloy with Sc addition will be remarkable improved.

Figure. 2 Microstructure of rolled alloys with different compositions:(a) 0Ag (7075), (b) 0.2Ag and (c) 0.4Ag [20]

\subsection{Rare Earth Elements}

There are 17 rare earth elements, which are the third subfamily of the periodic table. The addition of rare earth elements can purify, modify, microalloy, strengthen and improve the electrical conductivity of aluminum alloys. Depending on different performance needs of aluminum alloys, the mass fraction of rare earth elements in $0.1 \% \sim 0.4 \%$ is the best proportion[21]. Table3 [22] explained the characteristics of the main rare earth elements in aluminum.

Table. 3 Properties of major rare earth elements and their properties in aluminum[22]
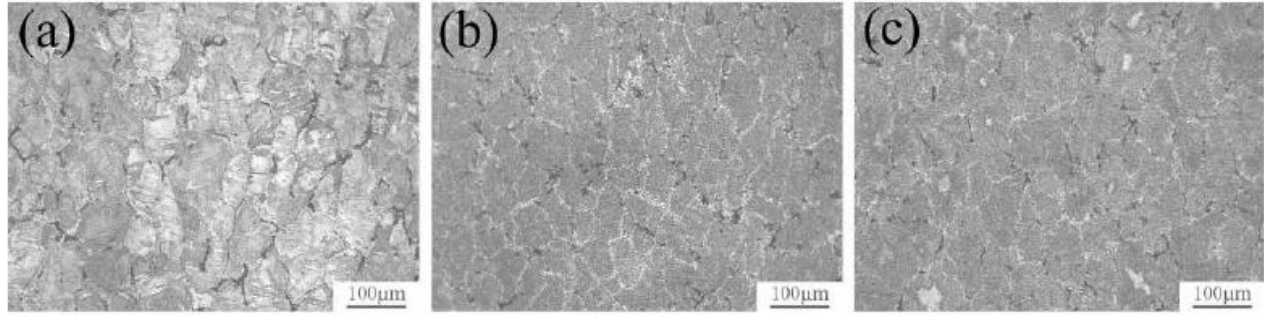


\subsubsection{Er}

Liu et al[23]. identified the effect of rare earth element Er on the failure behavior of $7 x x x$ series aluminum alloy. The results show that the addition of Er can can enhance strength of 7xxx series alloy. When $\mathrm{Zr}$ and rare earth elements coexist, the performance of the alloy gets better. When the mass fraction of $\mathrm{Zr}$ is $0.14 \%$, Er has a strong ability to improve strength (4.2\%). When the mass fraction of $\mathrm{Zr}$ is $0.27 \%$, Er has a weak ability to improve strength $(3.1 \%)$ trace addition of Er can improve the plasticity of the material; the fracture mechanism of the alloy without Er is brittle fracture and secondary cracks appear. The toughness of the alloy with trace addition of Er is enhanced, and dimples appear, which changes from brittle fracture to ductile fracture mode[24].

\subsubsection{Sc}

Li et al[25]. found that due to the decrease of recrystallization fraction and discontinuous distribution of GBPs, $0.06 \mathrm{wt} \%$ Sc addition to medium strength Al-Zn-Mg alloy has excellent SCC resistance under aging conditions. Excessive addition of $0.11 \mathrm{wt} \% \mathrm{Sc}$ can increase the electrochemical activity and hydrogen embrittlement rate of GBPs and PFZ, thereby reducing the SCC resistance of the alloy.

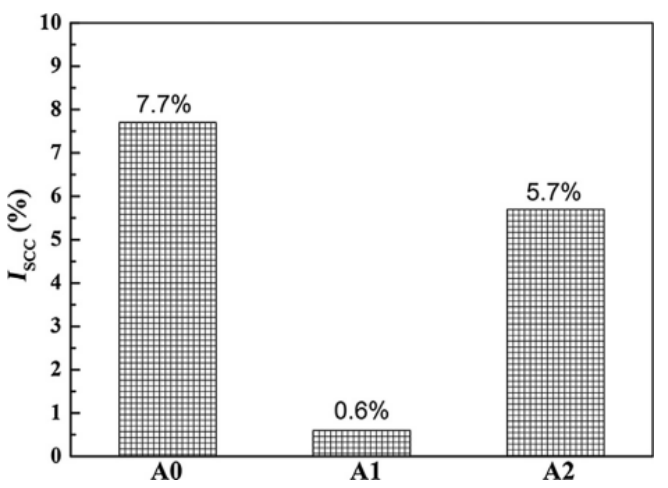

Figure. 3 SCC susceptibility index (ISCC) of three peak-aged alloys.For $\mathrm{Al} \mathrm{Zn} \mathrm{Mg}$ alloys with 0wt \% SC (A0), 0.06\% SC (A1) and $0.11 \%$ SC (A2)After homogenization treatment $\left(470^{\circ} \mathrm{C}\right.$ for $\left.24 \mathrm{~h}\right)$, the ingot is preheated at $450^{\circ} \mathrm{C}$ for $1 \mathrm{H}$.[25]
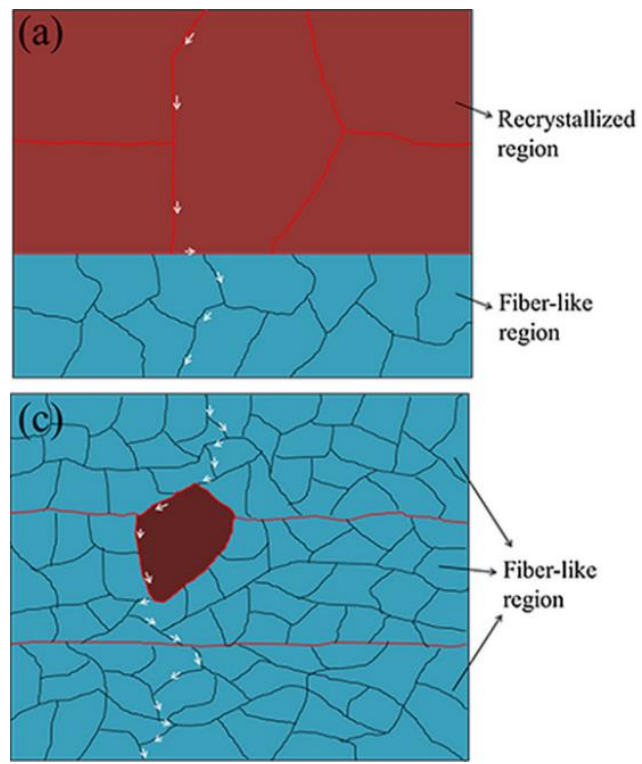

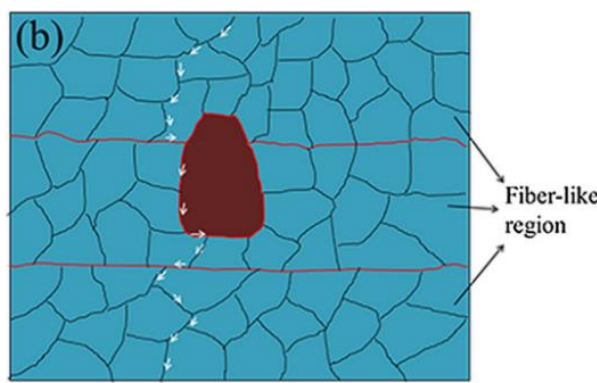

(d) HAGBs LAGBs

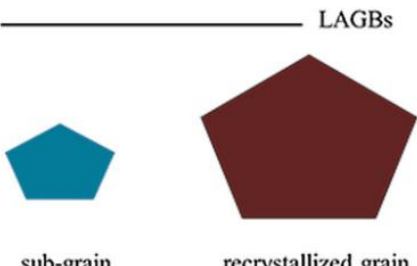

Figure. 4 Schematization of SCC crack propagation paths for three peak-aged alloys:(a) A0; (b) A1; (c) A2; (d) the type of GB and grain[25]. 
Figure 3 exhibition the peak SCC sensitivity index (ISCC) of the three alloys. Figure 4 shows the SCC crack growth path diagram of the three alloys. Due to the decrease of recrystallization fraction and the discontinuous distribution of GBPs, $0.06 w \mathrm{t} \% \mathrm{Sc}$ addition to medium strength $\mathrm{Al}-\mathrm{Zn}-\mathrm{Mg}$ alloy has superordinary SCC resistance and excellent mechanical properties even under aging conditions. Excessive addition of $0.11 \mathrm{wt} \%$ will increase the electrochemical activity and hydrogen embrittlement rate of GBPs and PFZ, and reduce the SCC resistance of the alloy.

\subsubsection{Sc and $\mathrm{Zr}$}

The addition of trace amounts of $\mathrm{Sc}$ and $\mathrm{Zr}$ in $\mathrm{Al} \mathrm{Zn}-\mathrm{Mg}-\mathrm{Cu}$ alloy is more beneficial to improve the extremely fine $\mathrm{Al}_{3}(\mathrm{Sc}, \mathrm{Zr})$ particles, and the alloy obtains higher strength and ductility, because the dispersed $\mathrm{Al}_{3}\left(\mathrm{Sc}, \mathrm{Zr}\right.$ ) particles with $\mathrm{L}_{2}$ structure are formed during homogenization. $\mathrm{Al}_{3}(\mathrm{Sc}, \mathrm{Zr})$ particles with $\mathrm{L}_{2}$ structure precipitated at any time into coherent $\mathrm{Al}_{3}(\mathrm{Sc}, \mathrm{Zr})$ particles with $\mathrm{DO}_{23}$ structure can effectively hinder recrystallization, inhibit grain growth, and improve the mechanical properties of the alloy[26]. Sc is a transitional element in rare earth elements and has been used as a kind effective grain refiner to replace $\mathrm{Ti} / \mathrm{TiB}$. Primary $\mathrm{Al}_{3} \mathrm{Sc}$ particles can be used for excellent heterogeneous nucleation and can effectively refine the grain size of aluminum alloy during solidification. In the Al-Sc binary system, the recrystallization can be effectively retained by adding $0.15 \%-0.20 \%$ Sc. Xiao et al. [27] found that compared with the addition of $0.10 \% \mathrm{Zr}$, the alloy with $0.07 \%$ Sc and $0.07 \% \mathrm{Zr}$ can resist recrystallization more effectively and improve the mechanical properties of 7xxx aluminum alloy.

\subsubsection{Y}

In recent years, it has been found that a small amount of $Y$ can refine the secondary dendrites of 7xxx alloy, reduce the size of eutectic compounds and improve the impact toughness of the alloy. According to the composition of the main alloy elements, $\mathrm{Al}_{3} \mathrm{Y}$, $\mathrm{Al}_{6} \mathrm{Cu}_{6} \mathrm{Y}$ or $\mathrm{Y}_{12} \mathrm{Al}_{3} \mathrm{Zn}$ rare earth compounds will be formed, which have an obvious effect on grain refinement. Li et al.[28] found that after adding $0.25 \mathrm{Er}$ and $0.15 \mathrm{Y}$ to $7 \mathrm{xxx}$ aluminum alloy, the dissolution temperature of eutectic compound increased, the nucleation rate increased, and the fine grain strengthening was achieved. Table 3 has pointed out that the atomic radius difference between $\mathrm{Y}$ atom and $\mathrm{Al}$ atom is $26 \%$. The deformation mechanism of $Y$ in 7xxx aluminum alloy is that when $Y$ atom enters the aluminum alloy, the lattice distortion and the free energy of the alloy increase, and the rare earth phase compounds containing Y can only be distributed at the grain boundary. Secondly, when $\mathrm{Y}$ enters the alloy, the second phase at the grain boundary increases, which inhibits the growth of grains. The generated $\mathrm{Al}_{3} \mathrm{Y}, \mathrm{Al}_{6} \mathrm{Cu}_{6} \mathrm{Y}$ or $\mathrm{Y}_{12} \mathrm{Al}_{3} \mathrm{Zn}$ rare earth compounds as the core of heterogeneous nucleation can strengthen the aluminum alloy. If the rare earth element $\mathrm{Y}$ is excessive, the second phase will be enriched and the comprehensive properties of the alloy will be greatly reduced. Due to the low price of rare earth element $Y$, it is an important additive element with potential for future development.

\subsubsection{Gd}

The rare earth element $\mathrm{Gd}$ also has a certain influence on the high temperature properties of the alloy. The addition of rare earth element Gd to the 7xxx series aluminum alloy forms a uniformly distributed $\mathrm{L1}_{2}$-type $\mathrm{Al}_{3}(\mathrm{Gd}, \mathrm{Zr})$ dispersed phase, rather than a core-shell-shaped $\mathrm{Al}_{3}(\mathrm{Sc}, \mathrm{Zr})$ dispersed phase produced by adding Sc element to the 7xxx series aluminum alloy. Chen[29]et al found that: The addition of $0.11 \% \mathrm{Gd}$ in $7 \mathrm{xxx}$ aluminum alloy has a significant effect on hindering dislocation and grain boundary movement, stabilizing a large number of deformation and recovery structures of fine subgrain boundaries. The stress corrosion crack propagation rate of the alloy was effectively delayed. The addition of $0.11 \%$ Gd element to 7056 aluminum alloy also increased the KI ( critical stress intensity factor ) of 7056 from $5.45 \mathrm{MPa} \cdot \mathrm{m}^{1 / 2}$ to $10.59 \mathrm{MPa} \cdot \mathrm{m}^{1 / 2}$. 
Figure. 5 Optical microstructures of the two studied alloys with solution treatment: (a) 0\%Gd and (b) 0.25\%Gd[30]

Mei et al.[30] found the Figure5 shows that after high temperature solution treatment, the alloy without Gd addition has fully recrystallized, forming equiaxed recrystallized grains, and the alloy with Gd addition still maintains fine fibrous unrecrystallization microstructure, indicating that the formed dispersion phase can effectively hinder the transformation of deformation recovery microstructure to subgrain microstructure, thereby inhibiting the recrystallization of the matrix. Shows that the rare earth element $\mathrm{Gd}$ is mainly distributed among dendrites in 7075 aluminum alloy with $\mathrm{Al}_{3} \mathrm{Gd}$ compound. Adding $\mathrm{Gd}$ within the effective range can improve the tensile strength and elongation of aluminum alloy.

\subsection{Non-Metallic Inclusions Element}

Fe and Si elements are harmful impurities in 7xxx aluminum alloys. The main phases of impurity elements $\mathrm{Si}$ and $\mathrm{Mg}$ in 7xxx aluminum alloys are brittle phases such as $\mathrm{Al}_{7} \mathrm{Cu}_{2} \mathrm{Fe}, \mathrm{MgSi}_{2}, \mathrm{AlFeMnSi}$ and eutectic compounds. Because the impurity particles containing Fe and Si are distributed inside the grains or on the grain boundaries and are difficult to dissolve at high temperature, it is easily occur produce the banded structure which is arranged intermittently along the deformation direction during hot deformation. In the process of plastic deformation, due to the uncoordinated deformation of the brittle phase matrix, microcracks are easily generated on some grain-matrix boundaries and become the source of macroscopic cracks, which has an unfavorable influence effect on the plasticity and fracture toughness of the alloy. At present, the mass fraction of $\mathrm{Fe}$ and $\mathrm{Si}$ impurities in 7xxxx series aluminum alloys should be limited to below $0.15 \%$.

\section{Aging Precipitation Sequence and strengthening-toughening mechanism of $7 x x x$ Series Aluminum Alloy}

The main phases that can be capabled between the elements of $\mathrm{Al}-\mathrm{Zn}-\mathrm{Mg}-\mathrm{Cu}$ quaternary alloy mainly include $\alpha$ phase (Al matrix), $\theta$ phase $\left(\mathrm{CuAl}_{2}\right), \mathrm{S}$ phase $\left(\mathrm{Al}_{2} \mathrm{CuMg}\right)$, $\eta$ phase $\left(\mathrm{MgZn}_{2}\right), \beta$ phase $\left(\mathrm{Al}_{8} \mathrm{Mg}_{5}\right)$ and $\mathrm{T}$ phase $\left(\mathrm{Al}_{2} \mathrm{Mg}_{2} \mathrm{Zn}_{3}\right)$. The precipitated phases affect the main properties of the material[31] .

\subsection{Precipitated Sequence}

Figure 6 shows the temperature dependence of Al-rich angle of equilibrium phase in 7xxx series aluminum alloys. According to the phase diagram, the increase of $\mathrm{Cu}$ content promotes the appearance of $\theta$ phase. When $\mathrm{Cu}$ is lower content, the phase composition is 
mainly affected by $\mathrm{Zn} / \mathrm{Mg}$ ratio. When the $\mathrm{Zn} / \mathrm{Mg}$ ratio is extremely small, all the amounts are composed of $\alpha+S+T$ phase or medium $\alpha+T$ phase without $\eta$ phase; when the $\mathrm{Zn} / \mathrm{Mg}$ ratio increased, nphase began to appear and gradually increased, accompanied by $S$ phase and $T$ phase.

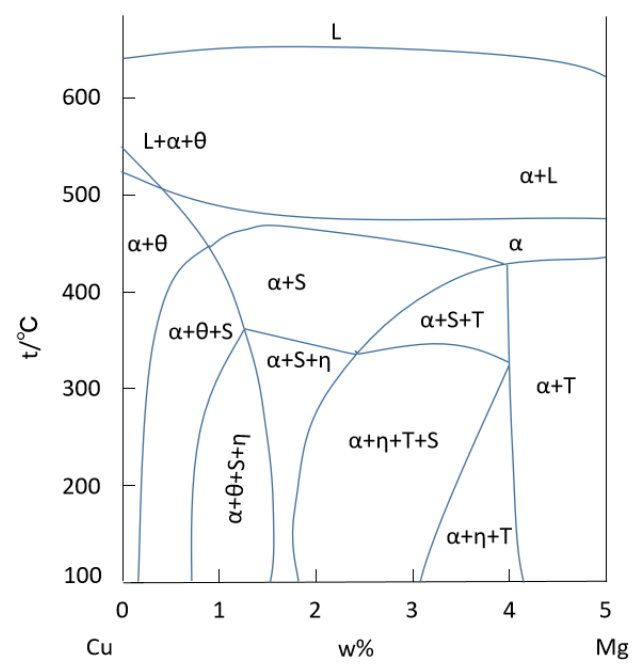

Figure.6 Variable temperature section of aluminum rich angle of equilibrium phase of 7xxx aluminum alloy[32]

The precipitation sequence of precipitates in 7xxx series aluminum alloy is classified into three types: the first is GP zone (supersaturated solid solution SSS $\rightarrow$ GP I zone $\rightarrow$ GP II zone $\rightarrow \eta$ ' phase $\rightarrow \eta$ phase ); the second is when the Mg content is high, supersaturated solid solution SSS appear defects and grain boundaries, the precipitation order is: ( supersaturated solid solution SSS $\rightarrow \mathrm{T}$ phase and macroscopic Al-Zn-Mg-Cu phase $\rightarrow \eta$ phase) ; finally, when the supersaturated solid solution SSS appears vacancy-rich region, the precipitation order is (SSS $\rightarrow$ VRC (vacancy-related cluster) vacancy enrichment $\rightarrow$ T phase and coarse Al-Zn-Mg-Cu phase $\rightarrow \eta$ phase) three kinds of different precipitation behavior, the three eventually formed a stable $\eta$ phase, the precipitation order is shown in Figure 7. The main strengthening phases of $\mathrm{Al}-\mathrm{Zn}-\mathrm{Mg}-\mathrm{Cu}$ alloy include GP zone and $\eta$ ' phase. The GP zone is a fully coherent Mg and $\mathrm{Zn}$ enrichment zone with the aluminum matrix, which is spherical (GP I zone) or strip (GP II zone), while the $\eta$ ' phase is a hexagonal plate metastable phase semi-coherent with the aluminum matrix, which is the uppermost aging strengthening phase. $\eta$ phase is a disc-shaped equilibrium phase that is not coherent with the matrix [33]. If there is $\mathrm{T}$ phase under certain composition conditions, $\eta$ phase will be replaced by T phase. Due to the existence of $\mathrm{Cu}$ atoms in the alloy, $\mathrm{S}$ phase will appear at the grain boundaries at a certain $\mathrm{Zn} / \mathrm{Mg}$ ratio. It will act as a cathode to continuously dissolve the surrounding matrix to form pitting corrosion, which will also lead to poor fracture properties of aluminum alloys. Table4 summarizes the main precipitated phases and their structure characteristics in 7xxx series aluminum alloys. 
It can be seen from Figure. 10 that when the temperature is lower than $100{ }^{\circ} \mathrm{C}$, the $\eta$ precipitates in the alloy are mainly V3 and V4. When the temperature range is $125-175{ }^{\circ} \mathrm{C}, \mathrm{V} 1$ and $\mathrm{V} 2$ is mainly contains $\eta$ precipitates $[39,43]$.

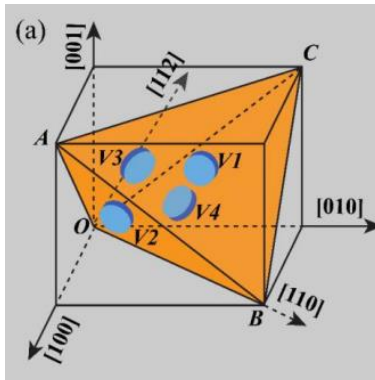

(b)

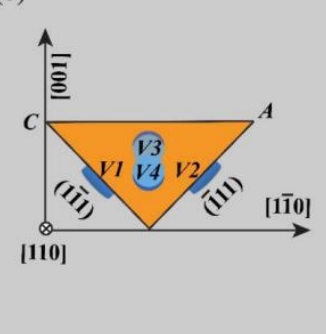

Figure 8 . Schematic illustrations showing four types of $\eta$ variants V1-4 on $\{111\}_{\mathrm{AI}}[39]$

(a) The threedimensional view, and (b) the projection from [110]Al direction

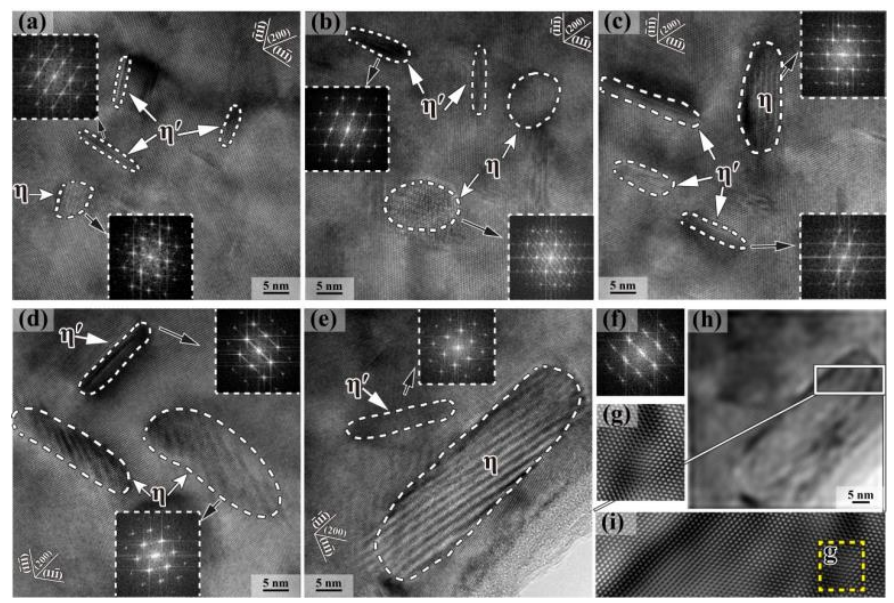

Figure 9. HRTEM images of the precipitates viewed along $<110>\mathrm{Al}$ orientation in 7085 alloy after various heat treatments:(a) sample I $\left(25^{\circ} \mathrm{C}\right)$, (b) sample II $\left(100^{\circ} \mathrm{C}\right)$, (c) sample III $\left(125^{\circ} \mathrm{C}\right)$, (d) sample IV $\left(150^{\circ} \mathrm{C}\right)$, (e) sample V $\left(175^{\circ} \mathrm{C}\right)$, (f) corresponding FFT pattern of $\eta$ phase in (e), (g) is from the yellow dashed frame in (i), (h) is the corresponding inverse FFTimage of (e), and (i) is from the white solid frame in (h) [39]

Figure 9(a) shows that $\eta$ ' phase is thin margin ( elongated ) on $\{111\}$ Al plane. The insertion of the upper left corner shows the fast fourier transform (FFT) pattern diagram of the $\eta$ ' phase with weak scattering. When the temperature reaches $175^{\circ} \mathrm{C}$ Figure10(e), $\eta^{\prime}$ thickness and radius increase respectively. A larger radius and thickness of $\eta$ precipitates can also be observed. The clearer observation results in Figure9(g) show the obvious aboriginal lattice distortion caused by the incoherence between $\eta$ phase and $\alpha$-Al matrix.

A. Khalfallah et al.[40] found by DSC that the formation of GP region is controlled by the migration of $\mathrm{Zn}$ and $\mathrm{Mg}$ atoms, while $\eta$ 'metastable and $\eta$ precipitation of stable phase is affected by the migration and diffusion of solute atoms. L. K. et. al [41] found that GP I region was formed in a wide temperature range from room temperature to $140-150^{\circ} \mathrm{C}$, and was independent of quenching temperature. These regions are consistent with the aluminum matrix. Based on the $\mathrm{AlCu}_{(\mathrm{I})}$ type subunit, the interior of the matrix lattice is arranged as $\mathrm{Zn}$ and $\mathrm{Al}$ or $\mathrm{Mg}$, and the periodic inverse boundary is formed after quenching above $450^{\circ} \mathrm{C}$ and aging above $70^{\circ} \mathrm{C}$. According to the diffraction theory, the GPII region is identified as a Zn-rich layer on the $\{111\}$ plane, the inside of which is arranged in a slender crystal orientation. The habit plane of GPII region is $\{111\}$ plane, indicating that not all GP regions can be transformed into $\eta^{\prime}$ phase. The $\eta^{\prime}$ phase is a seven-layer $\{111\}_{\mathrm{Al}}$ thick, with $\mathrm{O}$ ( orthorhombic) and $\mathrm{R}$ ( rhombohedral ) subunit units inside. Each ligand is formed by the push-ring contact between two atoms and six atoms. It can be seen that the GP zone with smaller size has higher surface energy, which 
is more unstable than the GP zone with larger size. With the aging process, the GP zone with smaller size is transformed into $\eta$ ' phase. Figure10 shows the lattice and crystal structure of 7xxx aluminum alloy under haddf-stem.
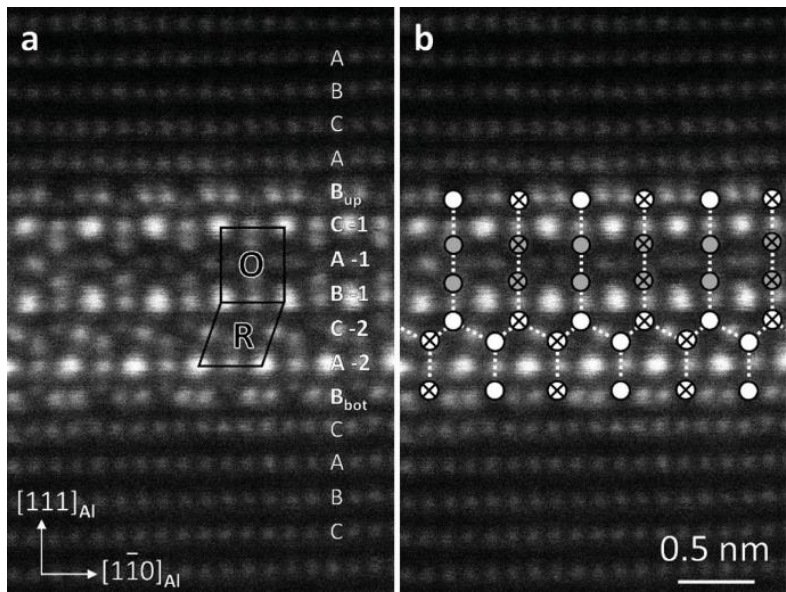

Figure10. Lattice and crystal structure of 7xxx aluminum alloy under haddf stem(a)STEM image of the $\eta$ precipitate showing the continuity of stacking of the fcc aluminium lattice. (b)Overlaid of thestructure's skeleton made up from the major ligands.[42]

\subsection{Strengthening and toughening mechanism}

\subsubsection{Strengthening}

The strengthening and toughening of 7xxx series aluminum alloy deformation mainly includes solid solution strengthening, second phase strengthening, grain boundary strengthening and processing strengthening. The existing problem is still that the comprehensive performance of strength and toughness and stress corrosion resistance are low.According to the aging precipitation [39,44-46], the phase, GBPs and PFZ of the precipitated alloy after aging determine the properties of the aluminum alloy. Reducing the slip of the eutectic surface and narrowing the PFZ of the grain boundary, optimizing the composition design of the alloy and improving the heat treatment method are the specific means to improve the comprehensive properties of the alloy[46]. Improving the properties of the aluminum alloy cannot only start from the composition design, but also understand the performance theory and characterization method of the microstructure in depth[47]. Dai et al.[48] researched the mechanical properties of 7xxx series aluminum alloy at $470^{\circ} \mathrm{C}$ under different solution time. With the extension of solution holding time, the tensile strength and elongation of the alloy increased first to the peak and then decreased gradually. Under $470^{\circ} \mathrm{C}$ solution state, the tensile strength and yield strength of the alloy were the highest when the aging time was $120 \mathrm{~min}$, which were $475.3 \mathrm{MPa}$ and 448.6 $\mathrm{MPa}$, respectively. After solution treatment and aging at $120^{\circ} \mathrm{C}$ for $24 \mathrm{~h}$, the tensile strength reached a peak of $613.5 \mathrm{MPa}$ at $120 \mathrm{~min}$, and the yield strength reached a peak of $578.5 \mathrm{MPa}$ at $160 \mathrm{~min}$. Figure 11 shows the changes of mechanical properties of the alloy at the peak point of tensile strength and yield strength at $470^{\circ} \mathrm{C}$ for different solution time. 
Figure. 11 Change of tensile properties of studied alloy with solution time at $470^{\circ} \mathrm{C}$ (a)solution (b)solution+T6[48]

When the second phase is uniformly distributed in the matrix with fine dispersed particles, the precipitation strengthening or aging strengthening (dislocation cutting through the second phase mechanism) occurs when the second phase precipitates and produces a strengthening phase through the aging treatment of the supersaturated solid solution. If the second phase particles are strengthened by powder metallurgy, it is called dispersion strengthening[45,49]. The elements of the material composition affect the strength of the second phase particles, grain boundaries, grain size and orientation, grain boundaries and separation and residual stress in the material. The formation of the second phase particles belongs to the diffusion-type phase transformation. When the dislocation meets the metastable precipitates such as $\eta^{\prime}(\mathrm{MgZn} 2)$ phase, $\eta_{\mathrm{p}}\left(\mathrm{Al}_{2} \mathrm{Mg}_{2} \mathrm{Zn} 8\right)$ phase, $\mathrm{S}^{\prime}\left(\mathrm{Al}_{2} \mathrm{CuMg}\right)$ phase, $\beta^{\prime}\left(\mathrm{Al}_{8} \mathrm{Mg}_{5}\right)$ phase and $\mathrm{T}^{\prime}\left(\mathrm{Al}_{2} \mathrm{Mg}_{2} \mathrm{Zn}_{3}\right)$ in $7 \mathrm{xxx}$ aluminum alloy, the dislocation will cut through the above metastable precipitates and deform with the matrix at the same time. The strength of the alloy is improved by increasing the interface energy between the second phase particles and the interface. When the dislocation meets the precipitated phase $\eta$ with larger steady-state size, it is incoherent with the matrix. The dislocation will be subjected to the second-phase particles to make the dislocation line bend larger and form the second-phase particle dislocation ring. Other dislocations bypass the second-phase particles. The effect of bypass mechanism on strengthening is enhanced with the increase of particles and the decrease of size [46].

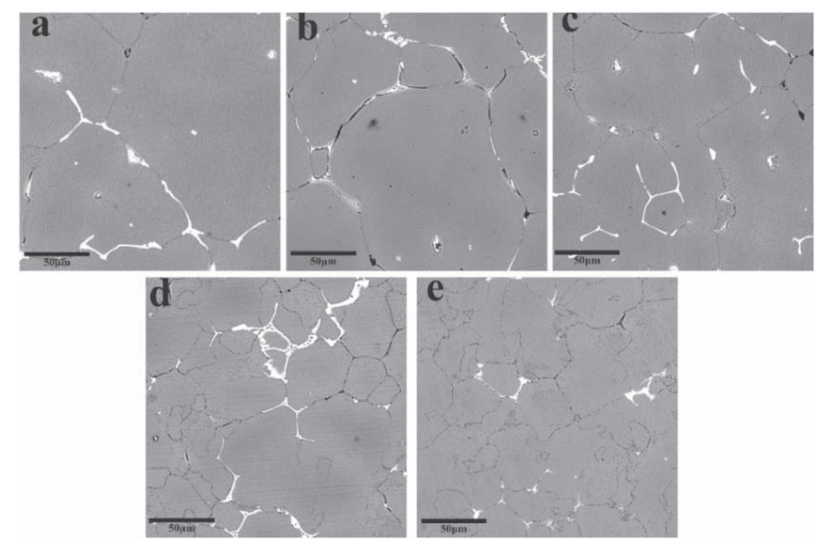

Figure 12. SEM images of 7055 as-cast alloys(a) Al-Y-0Sc, (b)Al-Y-0.2Sc, (c)Al-Y-0.25Sc, (d) Al-Y-0.3Sc, (e) Al-Y-0.35Sc.[50] 
Kai Huang [50]et al. found that when Sc content was up to $0.25 \%$, the grain dispersion strengthening refinement effect was effective, the particle size was more uniform, and the secondary dendrite spacing decreased. When the addition amount was more than $0.30 \%$, no grain refinement effect was observed as shown in Figure 12.
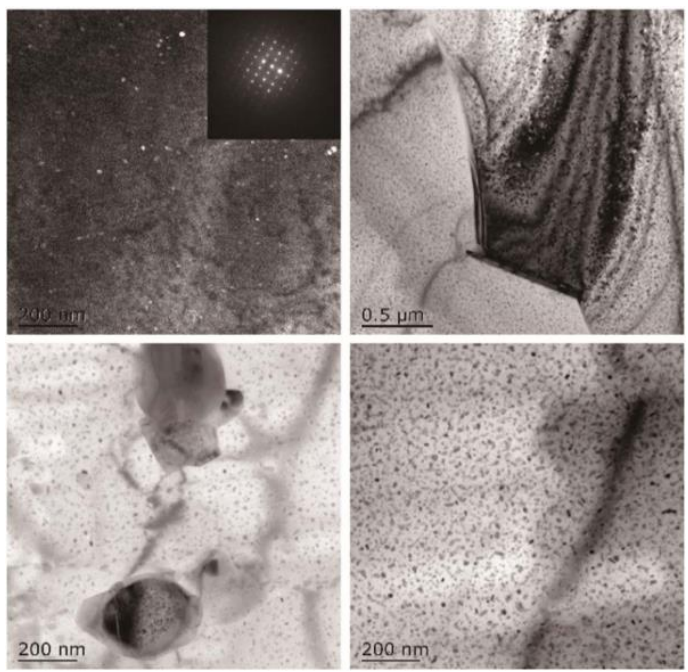

Figure 13. TEM topographic images of Al-0.25Y-0.25Sc alloy after aging[51]

Figure 13 shows the high density $\mathrm{Al}_{3}\left(\mathrm{~S}_{\mathrm{c}} \mathrm{Y}_{\mathrm{y}}\right)$ particles in Al-0.25Y-0.25Sc alloy grains, some of which are located in the dislocation position near GBs. The precipitates first precipitate and grow at GBs, and then transform into a stable phase by absorbing the solute atoms around the particles[51]. The second phase particles of $\mathrm{Al}_{3}\left(\mathrm{Sc}_{\mathrm{x}} \mathrm{Y}_{\mathrm{y}}\right)$ can prevent the movement of substructure and dislocation, and the alloy has the smallest particle size, so its corrosion resistance is the best. Zhang et al[52]. found that the second phase particles could inhibit the precipitation and aggregation of $\theta-\mathrm{CuAl}$ phase at GBs, which greatly reduced the corrosion sensitivity of the alloy. When the $\eta^{\prime}\left(\mathrm{MgZn}_{2}\right)$ phase is transformed into $\eta$ phase, the strength and plasticity of the alloy decrease instead. The $\eta$ phase distributed at the grain boundary will cause the formation of PFZ. Dislocation and stress concentration can lead to the expansion of PFZ into cracks[53].

Both grain boundary strengthening and processing strengthening strengthen the material by changing the grain size. The prominent role of melting and grain refinement in improving the mechanical properties of aluminum products is two key issues [54]. The most obvious improvement in grain refinement is the increase in strength at room temperature, which can be explained theoretically by the hall-petch formula. The ductility increases with the increase of grain number. Compared with the second phase strengthening and deformation hardening, the grain boundary strengthening can improve the strength, toughness and ductility, and reduce the defects such as separation and porosity of castings[55].

\subsubsection{Strengthening and toughening method}

The strengthening and toughening methods of 7xxx series aluminum alloys should not be limited to the simple design of the alloy composition in the "stir-frying style". We should focus more on the microstructure of the precipitates and the microstructure improvement methods after heat treatment. More attention should be paid to how to eliminate $S\left(\mathrm{Al}_{2} \mathrm{CuMg}\right)$ phase, $\theta\left(\mathrm{CuAl}_{2}\right)$ phase and $\mathrm{T}\left(\mathrm{Al}_{2} \mathrm{Mg}_{2} \mathrm{Zn} 3\right)$ phase, and how to control the content of $\mathrm{Mg} / \mathrm{Zn}$ to reduce the in-coherent precipitation caused by $\eta^{\prime}\left(\mathrm{MgZn}_{2}\right)$ phase. The addition of $\mathrm{Zr}$ and $\mathrm{Sc}$ atoms can form the dispersed $\mathrm{Al}_{3}(\mathrm{Sc}, \mathrm{Zr})$ particles that are coherent with the matrix, which can refine the grains and inhibit the recrystallization of the grain boundary. However, the transformation of $\mathrm{Al}_{3}(\mathrm{Sc}, \mathrm{Zr})$ particles from coherent to non-coherent should be avoided during the migration of the grain boundary. The 
non-coherent second phase particles will make the stress corrosion resistance of the material worse and the quenching sensitivity higher.

Secondly, the method of strengthening and toughening aluminum alloy should be combined with theoretical simulation and experiment, focusing on the optimization of 7xxx series aluminum alloy deformation processing and heat treatment on the microstructure and stress changes, Alistair Garne et al[56]. found the quenching of 7050 and 7085 aluminum alloypphase nucleation simulation Figure 14, obtained the quenching process between the two alloys q-GBPs (quenching state) and a-GBPs (aging state) composition in the volume composition difference. Menzemer et al[57]. studied the fracture surface morphology of 7085 at various temperatures, as shown in Figure.15 The alloy quenched in cold water showed the main intergranular fracture characteristics. When quenching in oil medium, the fracture surface transforms into a combination of transverse and intergranular fracture. It can be seen that heat treatment methods such as hierarchical solid solution and aging can promote the dispersion and homogenization of $\eta$ 'phase, and hinder the coarsening of PFZ region, thereby improving the strength and toughness of the alloy [58].

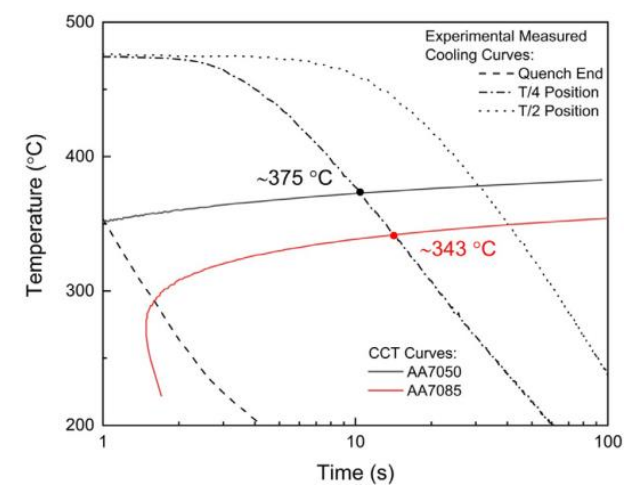

Figure 14. CCT curves for nucleation of $\eta$-phase Q-GBPs in AA7050 and AA7085[56]
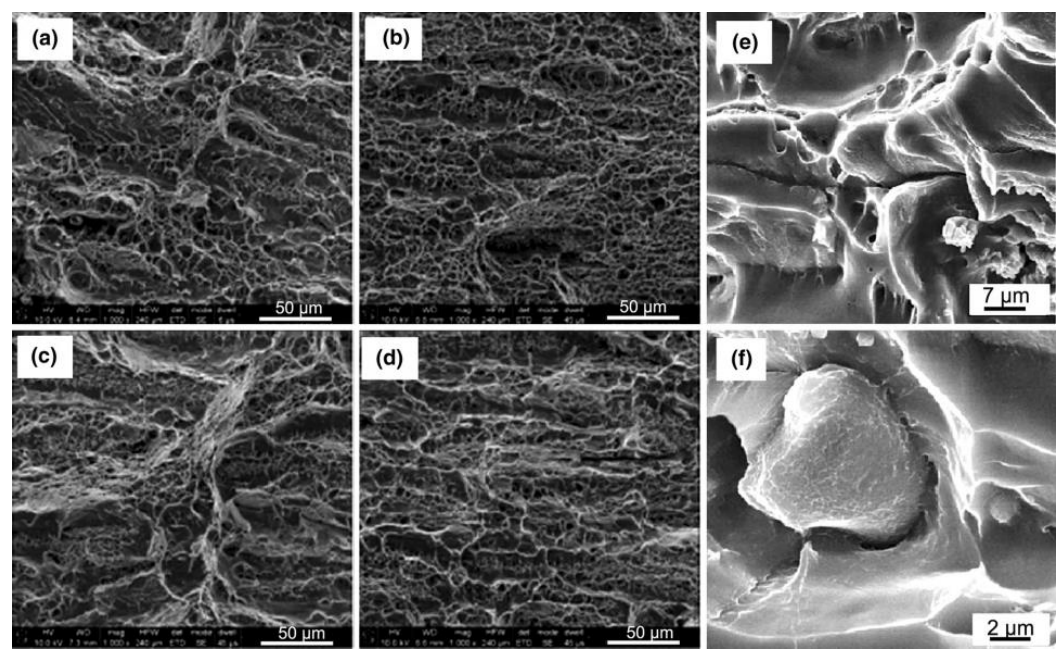

Figure. 15 Fracture surface morphologies of AA7085 Al alloy under conditions of T6(a), T74(b),RRA (c), HLA (d)temper conditions ; highmagnification images of fracture surface of AA7085 Al alloy show the cracking along the grain boundary triple points, dimples, and voids (e),cracking around coarse intermetallic particles (f)[57]

\subsubsection{First - Principle Calculation of Precipitation Strengthening Phase}

The first principle is based on the density functional theory (DFT), using the relativistic corrected projection augmented wave (PAW) method to describe the virtual element ratio, the crystal structure of the precipitated phase can be calculated and the stability of 
the crystal structure can be judged. Liu et al[59]. calculated the interface energy of $\mathrm{Al} /$ $\mathrm{Al}_{3} \mathrm{Sc}, \mathrm{Al} / \mathrm{Al}_{3} \mathrm{Er}$ and $\mathrm{Al}_{3} \mathrm{Sc} / \mathrm{Al}_{3} \mathrm{Er}$ in $\mathrm{Al}-\mathrm{Sc}-\mathrm{Er}$ alloy in three directions based on the PBE function in VASP software. It was found that the interface structure of ( 100 ) surface was the best, and the interface energy of $\mathrm{Al} / \mathrm{Al} 3 \mathrm{Er}$ was the largest as shown in Figure 16. The $\mathrm{L}_{12}-\mathrm{Al}_{3} \mathrm{Sc}_{x} \mathrm{Er}_{1-x}$ precipitates mainly formed the core-shell structure with $\mathrm{Al}_{3} \mathrm{Er}$ as the core and $\mathrm{Al}_{3} \mathrm{Sc}$ as the shell.
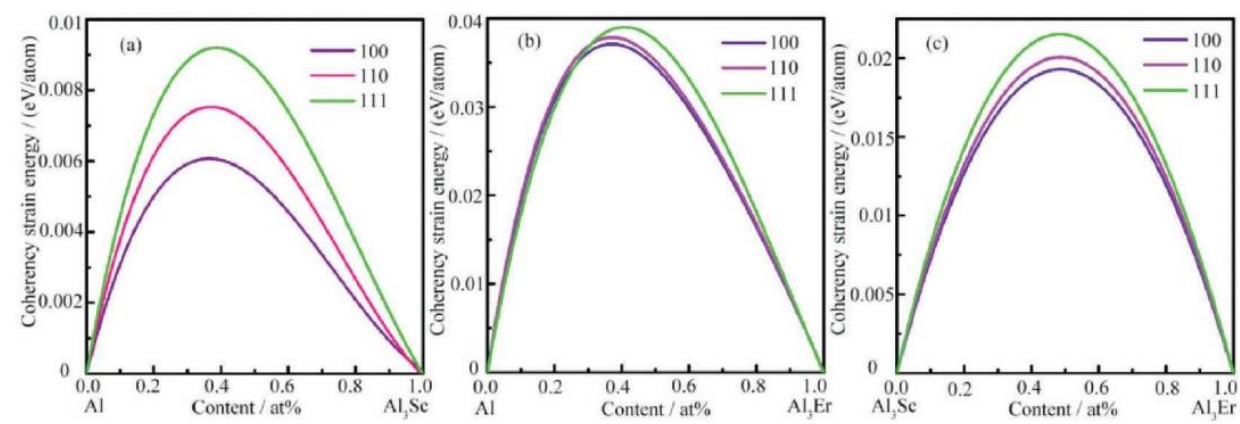

Figure 16. Coherency strain energies of (a)Al/Al $\mathrm{Al}_{3} \mathrm{Sc}(\mathrm{b}) \mathrm{Al} / \mathrm{Al}_{3} \mathrm{Er}(\mathrm{c}) \mathrm{Al}_{3} \mathrm{Sc} / \mathrm{Al}_{3} \mathrm{Er}$ on (100),(110),(111) interface planes[59]

Dong et al[60]. discussed the effect of doping elements (M) on the structural stability and mechanical properties of $\mathrm{Al}_{3} \mathrm{Sc}$ doped with $\mathrm{Zr}, \mathrm{Ti}, \mathrm{Y}$ and $\mathrm{L}$ as shown in Figure 16. The calculation shows that the structural stability, elastic properties and anisotropy of $\mathrm{Al}_{24} \mathrm{Sc}_{6} \mathrm{Zr}_{2}$ and $\mathrm{Al}_{24} \mathrm{Sc}_{6} \mathrm{Ti}_{2}$ are the superior. Sun et al[61]. calculated that the point defects of $\mathrm{L}_{12}-\mathrm{Al}_{3} \mathrm{Sc}$ were mainly $\mathrm{Al}$ vacancies and $\mathrm{Sc}$ antisite defects on the $\mathrm{Al}$ sublattice, as shown in Figure 17. Various mechanical properties of the material were calculated by the first principle method and the mechanical equation, which provided convenience for the study of the total amount and proportion of the main alloy elements of aluminum alloy, and was a new direction in the field of material design [45].

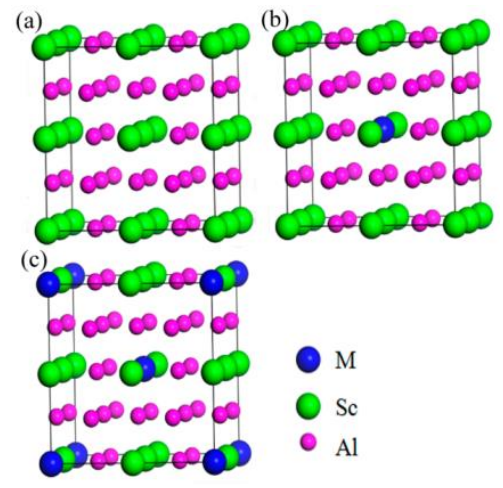

Figure 17 Structures of $\mathrm{Al}_{3} \mathrm{Sc}$ Cell structure of alloy elements $(\mathrm{M}=\mathrm{SC}, \mathrm{Zr}, \mathrm{Ti}, \mathrm{y}, \mathrm{Li})$ doped with different doping concentrations (a) $2 \times 2 \times 2$ surpercell; doped with the alloying element $(\mathrm{M}=\mathrm{Sc}, \mathrm{Zr}, \mathrm{Ti}$, $\mathrm{Y}, \mathrm{Li}$ ) at different doping concentrations, (b) $3.125 \%$, and (c) $6.25 \%$. Blue, green, and pink balls represent $(\mathrm{M}=\mathrm{Zr} / \mathrm{Ti} / \mathrm{Y} / \mathrm{Li})$, Sc, and $\mathrm{Al}$ atoms, accordingly [61]

\section{Preparation Method of 37xxx Series Aluminum Alloy}

7xxx series aluminum alloy Fe and Si element considered as a natural impurity, solid solubility at room temperature is extremely low insoluble intermetallic particles, insoluble intermetallic particles only through deformation and heat treatment to altere the morphology, crystal type and composition[62]. All coarse intermetallic particles are principal formed in the process of direct cold casting. The non-uniformity of alloy is the difficulty and critical in the design and preparation of large-scale materials. For avoiding performance loss in the manufacturing process. The integrated molding of materials is 
also a development trend. The sophisticated formation mechanism of macroscopic, microscopic and multi-scale structures involved in the relationship of alloy composition-process-structure-performance is the main reason for determining the properties of materials [63-64]. Figure18 shows the process-microstructure-performance relationship of 7xxx aluminum alloy.

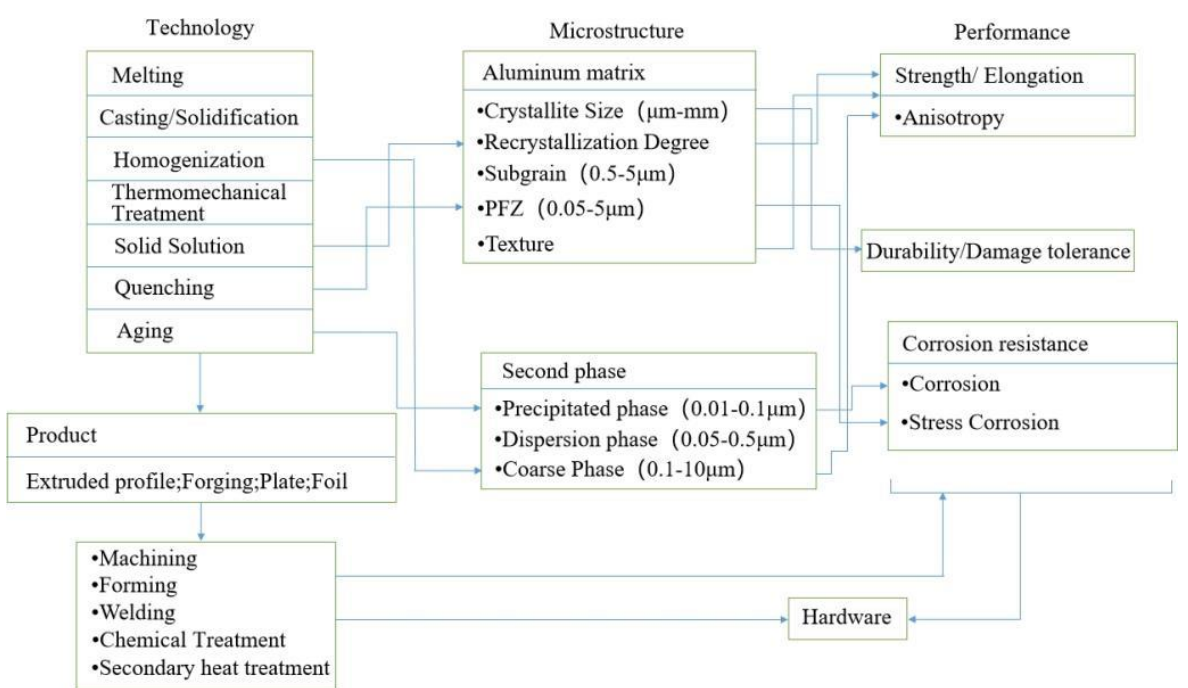

Figure 18. Technology microstructure performance relationship of 7xxx aluminum alloy[63]

\section{1 casting processes}

7xxx series aluminum alloy commonly used casting process is assigned to semicontinuous casting and squeeze casting. The casting structure is mainly consists of primary $\alpha-\mathrm{Al}, \mathrm{MgZn} 2, \mathrm{AlCuMg}, \mathrm{Al}_{2} \mathrm{Cu}$ and other second phases. With the decrease of pouring temperature, the primary $\alpha$-Al dendrites in the slurry gradually decrease, and the near-isometric primary phase gradually increases. The grain size decreases, and the average roundness increases. In the solidification process of casting, the equilibrium or metastable phase formed by liquid-solid eutectic reaction occurs [64-66]. Bai [67]measured the chemical mechanical properties of semi-solid 7050 alloy by in-situ solidification method. It was found that the tensile strength and plasticity of the alloy initially decreased sharply with the decrease of solid fraction, which was due to the sharp decrease of the degree of intercrystalline polymerization of the semi-solid alloy with the increase of liquid phase. The tensile strength of the alloy decreased only slightly, meanwhile the plasticity increased significantly. Thus, in the casting process should avoid the most is to eliminate macro segregation, cracks and other defects.

\section{2 multistage homogenization heat treatment of ingot}

7xxx series aluminum alloy has a high degree of alloying, and the dendrite segregation of chemical composition in the ingot is especially obvious. The ingot of this alloy must be homogenized in the processing process to eliminate the dendrite segregation of alloying elements and low melting point non-equilibrium eutectic phase, and reduce the heterogeneity of composition and structure. In practical engineering, the melting point of non-equilibrium eutectic phase is usually measured by differential thermal analysis (DTA) or differential scanning calorimetry (DSC) curve, and the melting temperature below the melting temperature of non-equilibrium eutectic phase is selected as the starting temperature of homogenization [68].

Secondly, another purpose of homogenization heat treatment is to regulate the behavior of high melting point precipitates of microalloying elements. The homogenization temperature of $7 x x x$ alloy ingots is usually below $470{ }^{\circ} \mathrm{C}$, because $480^{\circ} \mathrm{C}$ is considered to 
be the overburning temperature of 7xxx alloy [63,69], at which time a large amount of residual components may still exist. For large and thick aluminum alloy sheets or ingots of shape, it is difficult to synchronize the lifting and cooling rates in aluminum ingots, so it cannot be optimized only by single-stage homogenization. Wang et al. [70] found that the highest temperature of two-stage homogenization treatment of 7B04 aluminum alloy can reach $500^{\circ} \mathrm{C}$. The most appropriate homogenization heat treatment process is heating at $10^{\circ} \mathrm{C} / \mathrm{h}$ to $470^{\circ} \mathrm{C}$ for 64 hours, and then heating at $1{ }^{\circ} \mathrm{C} / \mathrm{h}$ to $500{ }^{\circ} \mathrm{C}$ for 10 hours. By comparing the non-equilibrium solidification components of 7B04 aluminum alloy ingot after ultra-high temperature homogenization at $500^{\circ} \mathrm{C}$ completely dissolved in the alloy matrix, the hot rolling plasticity is much better than that of the traditional hot rolling plasticity after homogenization at $470^{\circ} \mathrm{C}$.
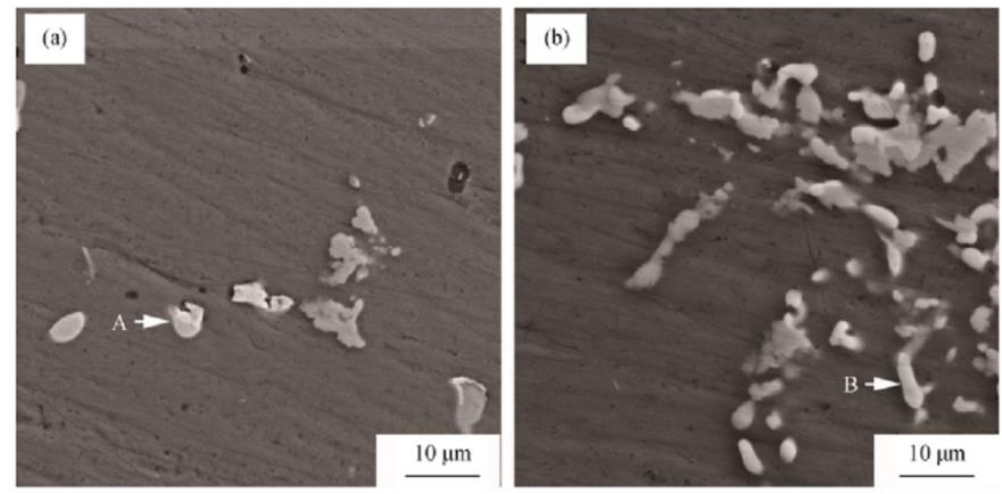

Figure. 19 SEM images of homogenized ingots: (a) 7055; (b) 7055-0.25Sc.[71]

The morphologies of 7055 and 7055-0.25Sc ingots after homogenization are shown in Figure 19[71] . The energy dispersive x-ray spectroscopy ( EDS ) spectrum of particle A, 12 ( a ) shows that the particle is in the $\theta$ phase.The EDS results measured by particle B (b) in Figure.19 correspond to w $(\mathrm{AlCuSc})$ phase. In the Al-Cu-Sc system with high copper content, Sc atoms diffuse to the $\theta$ phase, resulting in the transformation of $\theta$ phase into $\mathrm{w}$ phase during homogenization [72-73]. When the total mass fraction of Sc and Zr exceeds $0.45 \mathrm{wt} \%$, w phase, primary $\mathrm{Al}_{3}(\mathrm{Sc}, \mathrm{Zr})$ phase and refined grains are insufficient, and the mechanical properties of 7055-xZrySc rolled plate treated with T6 deteriorate, thus 7055-0.25Sc rolled plate shows the optimal mechanical properties in the prepared alloy.

\subsection{Deformation process}

The conventional deformation processes of 7xxx alloy, including equal channel angular pressing (ECAP), asynchronous rolling (ASR), high pressure torsion (HPT), accumulative roll-over (ARB) and reciprocating extrusion (CEC), include rolling, extrusion and forging. What required to research is eliminate the manufacturing defects through deformation process, and the production of ultra-fine grain microstructure resulting from work hardening and fine grain strengthening to improve the mechanical properties of materials and increase the precipitation density of $\eta$ ' phase, which is also far-reaching used strengthening method of alloy in industry.

Asynchronous rolling be called snake rolling according to the process characteristics. Asynchronous rolling introduces shear strain and increases the deformation of the core plate, which can effectively solve the serious uneven strain distribution of aluminum alloy plate in the symmetric rolling process. Xu et al.[74] found that the strength performance of the alloy plate increased with the increase of the speed ratio, and the elongation and fracture toughness decreased. When the speed ratio is the same, with the increase of offset, the strength of serpentine rolled sheet decreases, the elongation and fracture toughness increase significantly. In the condition offset $10 \mathrm{~mm}$ and speed ratio $1: 1$, the crack unit nucleation energy of serpentine rolled sample increases by $14 \% \sim 36 \%$. Xia 
[75]simulated the asynchronous rolling of magnesium alloy sheets. The results show that under the condition of the same total deformation, the multi-pass asynchronous rolling with small speed ratio can not only effectively obtain large shear strain accumulation, but also the distribution of equivalent strain is more uniform than that of large speed ratio rolling, and the multi-pass alternating asynchronous rolling can significantly improve the high uniformity of thick plates.

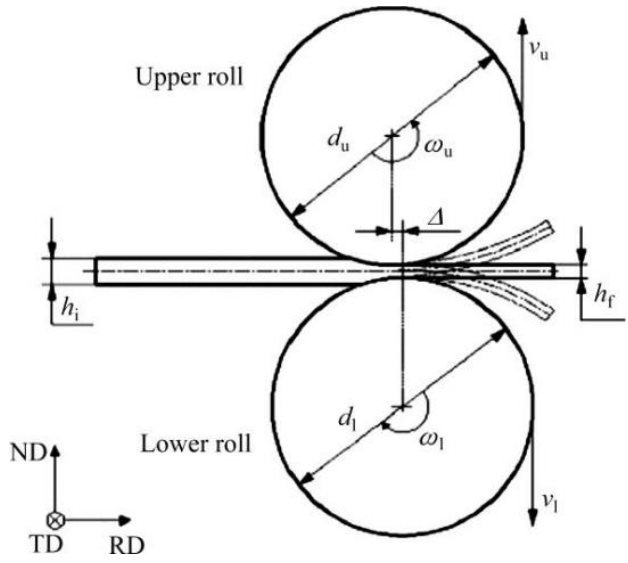

Figure. 20 Schematic diagram of snake rolling[76]

Figure 20 shows the schematic diagram of snake rolling[76]. As shown in the figure, the lower moves a distance $(\Delta)$ horizontally relative to the upper roller, and the peripheral speed ratio $(\mathrm{vu} / \mathrm{vl})$ between the upper and lower rollers be adjusted by altering the speed ratio $(\omega \mathrm{u} / \omega \mathrm{l})$ or diameter $(\mathrm{du} / \mathrm{dl})$. Extensive studies have shown that the snake rolling method can not only refine the grain, but also change the crystal structure [77-79].

\subsection{Heat treatment method}

The purpose of heat treatment is adjust the method suitable for material properties according to grain size, solute atoms, GBPs and microstructure of precipitates, mainly including solid solution treatment and artificial aging treatment. Such as single-stage and multi-stage solution, peak aging, excessive aging, multi-stage aging and regression reaging are widely applicable methods.

\subsection{1 solution treatment}

Solid solution treatment, known as quenching, is the basis of strengthening heat treatment (quenching and aging) of aluminum alloy strengthened by heat treatment [80]. Solid solution treatment is classified into single-stage solid solution treatment (SST), enhanced solid solution treatment (EST), high temperature pre-precipitation (HTPP) and multi-stage solid solution treatment (MST) [81-83].The objective of solid solution is to dissolve the alloying elements into the aluminum matrix to achieve a well strengthening effect in the subsequent aging precipitation stage. The single-stage temperature and constant-temperature multi-stage solid solution method can effectively alleviate the coarsening of alloy grains at high temperature. In multi-stage solution treatment (MST), the heating and holding process is divided into several stages from low temperature to high temperature, which can make the comprehensive performance of aluminum alloy more significantly improved. Feng et al.[81] used $\left(470^{\circ} \mathrm{C}, 1 \mathrm{H}\right)+\left(480^{\circ} \mathrm{C}, 1 \mathrm{H}\right)$ two-stage solid solution treatment for 7A55 alloy to eliminate the non-equilibrium of the surface layer of 7A55 aluminum alloy thick plate $\eta$ ' With high phase volume fraction, the heterogeneity of hardness and conductivity of 7A55 aluminum alloy thick plate be improved. The commonly used solid solution process of 7xxx aluminum alloy is [84-85] $450{ }^{\circ} \mathrm{C} / 2 \mathrm{~h}+$ $460^{\circ} \mathrm{C} / 2 \mathrm{~h}+470{ }^{\circ} \mathrm{C} / 2 \mathrm{~h}+480^{\circ} \mathrm{C} / 2 \mathrm{~h}$. After water-cooled solid solution strengthening and $121^{\circ} \mathrm{C} / 12 \mathrm{~h}$ aging treatment, the alloy can obtain better mechanical properties, and the 
strength, hardness and plasticity get superior. Figure21[86]shows the second phase distribution after different solid solution treatments. It can be seen that the solution treatment will significantly affect the grain size of the alloy and the solid solution degree of the solute atoms, thus changing the precipitation kinetics of the alloy in the subsequent aging process, and the number and density of the aging precipitates will ultimately determine the overall performance of the alloy.

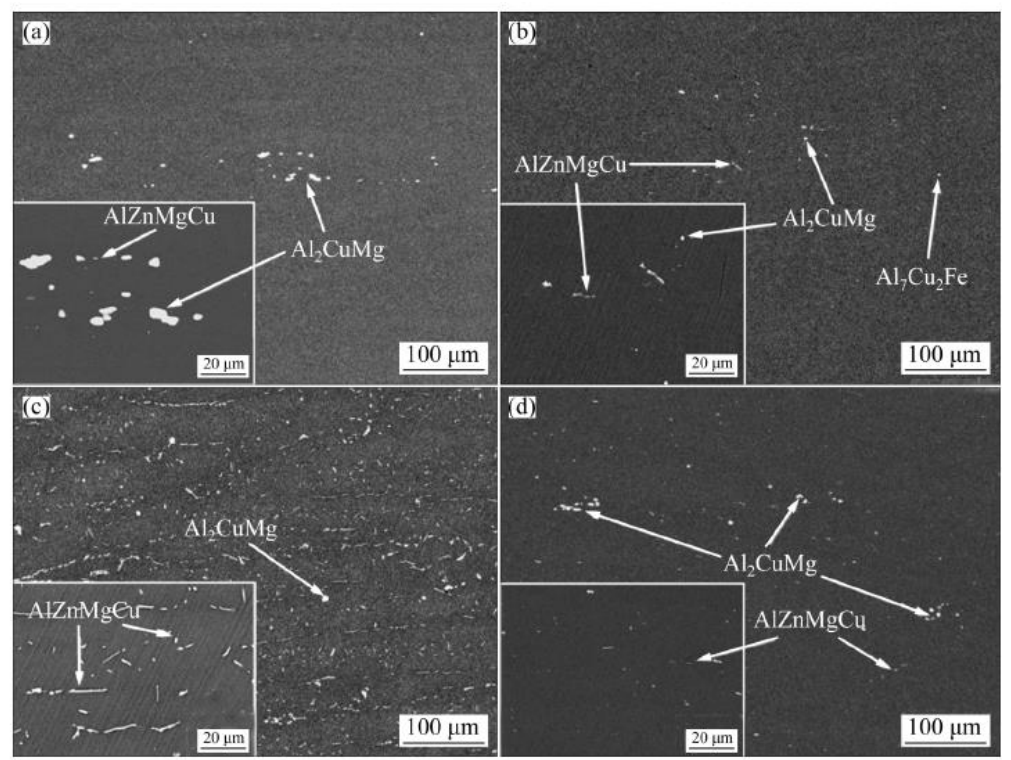

Figure.21 Second-phase distribution after different solid solution treatments in 7055:

(a) SST; (b) EST; (c) HTPP; (d) MST[86]

\subsubsection{Aging treatment}

The traditional 7xxx series aluminum alloy has high strength after peak aging (T6) treatment, but its SCC performance is low. Although overaging treatment can greatly improve the corrosion resistance of the alloy, the strength loss is large. In order to solve this problem, regression reaging (RRA) is introduced to balance the properties of materials [87-88]. Zheng et al[89]. improved T6176 intermittent aging system for 7475 aluminum alloy thick plate, and obtained the strength equivalent of T6 state and the local corrosion performance better than that of T73. Aging is a non-isothermal process. Ding [90]identified the effects of T6, four-stage aging, three-stage aging and T74 on thermal stability by tensile test, transmission electron microscopy (TEM) and atomic probe tomography (APT). The results showed that the tensile strength of the four-stage aging sample decreased by only $5.05 \%$ after thermal exposure at $120{ }^{\circ} \mathrm{Cfor} 500 \mathrm{~h}$. For the regression re-aging (RRA) treatment with stricter control of heat treatment time, the temperature of this process is high, and the precipitated phase will experience multiple reactions of dissolution, nucleation, growth and coarsening respectively or simultaneously in different regression temperature ranges. The hardness of 7xxx series aluminum alloy is higher than that of T651 (HV180) when the RRA heat treatment is carried out at a relatively low temperature $\left(180^{\circ} \mathrm{C}\right)$ and a short degradation period. However, with the increase of temperature, the hardness decreases with the increase of degradation period. After RRA treatment at $180^{\circ} \mathrm{C}$ for $4 \mathrm{~min}$, the hardness is the highest. The hardness of $7 \mathrm{xxx}$ series aluminum alloy is higher than that of T651 (HV180) when RRA heat treatment is carried out at a relatively low temperature $\left(180^{\circ} \mathrm{C}\right)$ and a short degradation period, but with the increase of temperature, the hardness decreases with the increase of degradation period, and the hardness reaches the highest after RRA heat treatment at $180{ }^{\circ} \mathrm{Cfor} 4$ min [63,91].Liao [92] carried out different combinations of pre-aging, regression treatment and re-aging systems on 7055, and obtained the optimum RRA system for the actual production of the factory is $120{ }^{\circ} \mathrm{C} / 24 \mathrm{~h}+175{ }^{\circ} \mathrm{C} / 1.5 \mathrm{~h}+120{ }^{\circ} \mathrm{C} / 24 \mathrm{~h}$, in which the 
heating rate is $35^{\circ} \mathrm{C} / \mathrm{h}$, and the cooling method is air cooling. The results show that the pre-aging temperature has more effect on the size of the precipitated phase than the re-aging temperature. After RRA treatment[93] , the material will be over-aged. During the re-aging process, a new precipitate occurs in the $\eta$ ' phase, while the coarse $\eta$ ' precipitate grows and transforms into the $\eta$ phase. It shows the regression stage undergoes heating, heat preservation, cooling and other processes, and there are many kinds of precipitates in the crystal, and the evolution law is sophisticated. However, the precipitation is a single type of equilibrium. Therefore, for the RRA treatment, the grain boundary precipitates can be selected as the object, and the non-isothermal regression kinetic model can be established to guide the precise regulation of aging process parameters.

\section{Challenges and Conclusion}

The optimization of alloy composition design and improvement of heat treatment method are the specific means to improve the comprehensive performance of 7xxx series aluminum alloy. The breakthrough of aluminum alloy composition design-microstructure characterization theory and research method promotes the development process of high strength aluminum alloy. To investigate the total amount and proportion of main alloy elements and the action law of microalloying elements, Thermo-Calc, VASP, Factsage, Materials Studio and other software be employed to integrate theoretical calculation, simulation and experiment. The research and development, performance improvement and product development period of 7xxx series new grade alloy be consumedly shorten and the efficiency immensely improved. Based on the research content, the research directions and methods of 7xxxx series aluminum alloys in the future are determined as follows :

- Under the guidance of the calculation results of the first-principles theory, the innovative design of the principal components and microalloying components of aluminum alloys was carried out. The microstructure-property characterization method of aluminum alloy was continuously improved according to the relationship among alloy composition, process, microstructure and property. The new principle and characterization method of the process-microstructure-property correlation of materials were developed to explore the characteristic microstructure $7 x x x$ aluminum alloy materials with high static strength, high strength, heat resistance, high toughness, damage resistance, low density, low quenching sensitivity and high comprehensive performance developed in the frontier;

- The width, GBps sum, distribution and continuity of the average PFZ determine the overall performance of the material. More attention should be paid to how to simultaneously improve the corrosion resistance and strength at the same time;

- Although the heat treatment process of 7xxx series aluminum alloy require to elapse the process of heating, holding and cooling, and there are many species precipitates in the crystal and the evolution mechanism is heterogeneous, the precipitated strengthening phase is a single type of equilibrium $\eta$ phase. Therefore, for the heat treatment process, the grain boundary precipitatesbe selected as the object, and the non-isothermal regression kinetic model was established to guide the accurate regulation of aging process parameters. More attention should be paid to how to increase the volume fraction of $\eta$ ' precipitates and modify the comprehensive performance of the material by regression reaging method.

Author Contributions: Conceptualization, investigation, writing - original draft preparation, Y.D.; data treatment, writing - review and editing, L.Y.; data treatment, J.H. All authors have read and agreed to the published version of the manuscript.

Funding: This research was funded by National Natural Science Foundation of China (Grant No.51764043); Scientific and Technological Program of Innovation and Guidance of Inner Mongolia 
(Grant No. KCBJ2018017); Inner Mongolia Youth Talent Program of Science and Technology (NJYT-20-A16); Inner Mongolia Natural Science and Technology (Grant No.2020MS05061)

Data Availability Statement: Not applicable.

Conflicts of Interest: The authors declare no conflict of interest.

1. Azarniya.; Abolfazl, T.; Karimi, T.; Kourosh, K. Recent advances in ageing of 7xxx series aluminum alloys: A physical metallurgy perspective. J Alloy Compd. 2019, 781, 945-983.

2. Prabhu, T.R. An Overview of High-Performance Aircraft Structural Al Alloy-AA7085. Acta Metall Sin. 2015, $28,909-921$.

3. Li, L.; Dong, L.; Wang, H.D.; Zhou, Y.X;. Gao, C.; Research progress on corrosion fatigue of aerospace aluminum alloy. Surf Technol. 2021, 7, 106-118.

4. UmamaheshweRrao, A.C.; Vasu, M.; Govindaraju, K.V.; SaiSrinadh.; Stress corrosion cracking behaviour of 7xxx aluminum alloys: A literature review. T Nonferr Metal Soc. 2016, 26, 1447-1471.

5. Xu, X.F.; Zhao, Y.G.; Zhang, M.; Ning, Y.H.; Wang, X.D. Effect of extrusion ratio on the microstructure and mechanical properties in an Al-Cu-Mg-Ag alloy. J Wuhan Univ Technol. 2018, 33, 710-714.

6. Zhang, X.L.; Chen, S.Y.; Zhou, L.; Fan, S.M.; Chen, K.H. Effect of composition on quenching sensitivity and microstructures-properties of super-strength Al-Zn-Mg-Cu aluminum alloys. Rare Metals. 2019, 43, 561-570.

7. Wang, Y.C.; Cao, L.F.; Wu, X.D.; Zou, Y.; Huang, G.J. Research progress on microstructure and properties of 7xxx series aluminum alloys for oil drill Pipes. Mater Rev. 2019, 33, 1190-1197.

8. Li, Y. Effect of Alloy elements on microstructure and hot tearing susceptibility in direct-chill casting of 7xxx aluminum alloys. Doctor's Thesis, University of Science and Technology Beijing, Beijing, China. 2019.

9. Dai, X.Y.; Li, N.; Xiong, L. Research progress of hardenability of Al-Cu-Mg-Ag alloys. Mater Rev. 2015, 29, 75-80+100.

10. Zhao, Q.; Wang, S.X. Selection and design of aluminum alloy, 1st ed.; Chemical Industry Press: Beijing, China, 2017; PP.34-35

11. Fang, H.C.; Yang, H.L.; Zhu, J.M.; Xiao, P.; Chen, Z.; L, T. Effect of minor Cr, Mn, Zr or Ti on recrystalliza tion, secondary phases and fracture behaviour of Al-Zn-Mg-Cu-Yb Alloys. Rare Metal Mat Eng. 2020, 49, 797-810.

12. Pan, Y.L. Study on compositonal design, microstructure and properties of novel high-strenghness Al-Zn-Mg-Cu aluminum alloy with good weldability and corrosion resistance. Doctor's Thesis,University of Science and Technology Beijing, Beijing, China. 2021.

13. Bhuiyan.,Toda, S;.Uesugi, H.;Takeuchi, K;.Watanabe, A.;Yoshio. Damage micromechanisms in high Mn and Zn content 7XXX aluminum alloys. Mater Sci Eng A. 2020, 793, 139423.

14. Valeev, I.S.; Barykin, N.P.; Trifonov, V.G. Valeeva, A.K. Effect of powerful current pulses on the structure and mechanical properties of the aluminum alloy Al-6\%Mg-0.6\%Mn. J Mater Eng Perform. 2014, 14, 236-240.

15. Wang, Z.P.; Wang, M.L.; Li, Y.G. Xiao, H.Y.; Chen, H.; Geng, J.W.; Li, X.F.; Chen, D.; Wang, H.W. Effect of pretreatment on microstructural stability and mechanical property in a spray formed Al-Zn-Mg-Cu alloy. Mater Design. 2021, $203,109618$.

16. Hu, G.Y.; Zhu, C.Z.; Xu, D.F.; Dong, P.X.; Chen, K.H. Effect of cerium on microstructure, mechanical properties and corrosion properties of Al-Zn-Mg alloy. J Rare Earth. 2021, 39, 208-216.

17. Chai, W.R.; Chen, J.C.; Liu, S.D.; Ye, L.Y.; Lin, H.Q.; ZHANG, X.M.; Effect of minor Zr addition on exfoliation corrosion resistance of Al-Zn-Mg-Mn alloy sheet. Chin J Mater Res. 2019, 33, 488-496.

18. Fang, H.C.; Chao, H.; Chen, K.H,; Zhang, Z. Microstructures, fracture and localized corrosion behaviors of Al-Zn-Mg-Cu alloy with $\mathrm{Zr}$, $\mathrm{Yb}$ and $\mathrm{Cr}$ additions. Rare Metals. 2015, 39, 686-695.

19. Feng, C.; Shou, W.B.; Liu, H.Q.; Yi, D.Q.; Feng, Y.R. Microstructure and mechanical properties of high strength $\mathrm{Al}-\mathrm{Zn}-\mathrm{Mg}-\mathrm{Cu}$ alloys used for oil drill pipes. T Nonferr Metal Soc. 2015, 25, 3515-3522.

20. $\mathrm{Xu}, \mathrm{X} . \mathrm{F}$. Study on the microstructure evolution and toughening-strengthening in $\mathrm{Al}-\mathrm{Cu}-\mathrm{Mg}-(\mathrm{Ag}) / \mathrm{Al}-\mathrm{Zn}-\mathrm{Mg}-\mathrm{Cu}-(\mathrm{Ag})$ alloys Doctor's Thesis, Jilin University, Jilin, China. 2015.

21. Yu, C. Chen, L.P.; Zhou, Q. Research progress in effects of rare earth elements on microstructure and properties of aluminum alloy. Spec Cast Nonferrous Alloys. 2021, 41, 241-246.

22. Wang, D.W.; Fu, Y.D.; Li, T.; Cong, F.G. Role of rare earth elements in wrought aluminum alloys and their development trend. Light Alloy Fabr. Technol. 2020, 48, 19-24+31.

23. Liu, L.H.; Liu, L.F.; Cao, F.H.; Yang, T.; Yin, P.Z. Effect of Er element on impact deformation and failure behaviors of 7xxx series aluminum alloy. Ordnance Mater Sci Eng. 2020, 43, 125-130.

24. Huang, Y.C.; Zhang, C.C.; Ren, X.W.; Liu, Y.; Chen, S.Z.; Wang, Y.L.; Existence form of trace Er in Al-Zn-Mg-Cu alloy and its "genetic effect". Rare Metal Mat Eng. 2019, 48, 2848-2856.

25. Li, Z.M.; Jiang, H.C.; Wang, Y.L.; Zhang, D.; Yan, D.S.; Rong, L.J. Effect of minor Sc addition on microstructure and stress corrosion cracking behavior of medium strength Al-Zn-Mg alloy. J Mater Sci Technol. 2018, 34, 1172-1179.

26. Liu, L. Sc and Zr microalloying effects and microscopic mechanisms in al alloys. Doctor's Thesis. Harbin Institute of Technology, Harbin, China. 2020.

27. Xiao, Q.F.; Huang, J.W.; Jiang, Y.G.; Jiang, F.Q.; Wu, Y.F.; Xu, G.F. Effects of minor Sc and Zr additions on mechanical properties and microstructure evolution of Al-Zn-Mg-Cu alloys. T Nonferr Metal Soc. 2020, 30, 1429-1438. 
28. Li, G.F.; Zhang, X.M.; Zhu, H.F. Effect of minor Er and Y additions to Al-Zn-Mg-Cu-Zr alloy on homogenizing behavior. Aeronaut Mater. 2010, 30, 1-6.

29. Chen, K.H.; Jian, S.S.; Zhou, L.; Chen, S.Y.; Huang, L.P. Effect of trace rare earth element Gd on microstructureand corrosion resistance of 7056 aluminum alloy. J Hunan Univ: Nat Sci Ed. 2020, 47, 96-107.

30. Mei, F.Q.; Wang, S.H.; Fang, C.F.; Meng, L.G.; Jia, F.; Hao, H.; Zhang, X.G. Effect of Gd content on microstructures and mechanical properties of Al-Zn-Mg-Cu-Zr alloys. Chin J Nonferrous Met. 2012, 22, 2439-2447.

31. Rokhlin, L.L.; Dobatkina, T.V.; Bochvar, N.R. Investigation of phase equilibria in alloys of the Al-Zn-Mg-Cu-Zr-Sc system. J Alloy Compd. 2004, 367, 10-16.

32. Zhang, X.M.; Deng, Y.L. China's strategic emerging industry-new alloy materials. 1st ed.; China railway publishing house: Beijing, China, 2018; PP.25-26.

33. Won, S.J.; So, H.K.; Leeseung, O.; Soong, J.K.; Kyou, H. Development of a high-strength Al-Zn-Mg-Cu-based alloy via multi-strengthening mechanisms. Scripta Mater. 2021, 205, 114216.

34. Yu, X.W. Study on the relationship between 3D microstructure and properties of Al- $\mathrm{Zn}-\mathrm{Mg}-(\mathrm{Cu})$ alloy during pre-deformation and aging. Doctor's Thesis. Hunan University, Hunan, China. 2020.

35. Priya, P.; Johnson, D.R.; Krane, M.J.M. Precipitation during cooling of 7xxx aluminum alloys. Comp Mater Sci. 2017, 139, 273-284.

36. Zhang, Y.; Li, H.P.; Kang, W.; Zhang, X.M. Aging microstructure evolution in high strength aluminum alloys and performance controlling. Chin J Nonferrous Met. 2017, 27, 1323-1336.

37. Yu, X.W.; Chen, J.H.; Ming, W.Q.; Yang, X.B.; Zhao, T.T.; Shen, R.H.; He, Y.T.; Wu, C.L. Revisiting the Hierarchical Microstructures of an Al-Zn-Mg Alloy fabricated by pre-deformation and aging. Acta Metall Sin-Engl. 2020, 33, $1518-1526$.

38. Bakhshi, R.; Farshidi, M.H.; Sajjadi, S.A. Strengthening of aluminium alloy 7005 through the imposition of severe plastic deformation supplemented by different ageing treatments. Chin J Nonferrous Met. 2021, 31, 2909-2921.

39. Zang, J.X.; Dai, P.; Yang, Y.Q.; Liu, S.; Huang, B.; Ru, J.G.; Luo, X. Study on the Relationship between High Temperature Mechanical Properties and Precipitates Evolution of 7085 Al Alloy after Long Time Thermal Exposures. Metals-Basel. 2021, 11, 1483.

40. Khalfallah. A.; Raho, A.A.; Amzert. S.; Djemli, A. Precipitation kinetics of GP zones, metastable $\eta^{\prime}$ phase and equilibrium $\eta$ phase in Al-5.46wt.\%Zn-1.67wt.\%Mg alloy. T Nonferr Metal Soc. 2019, 29, 233-241.

41. Berg, L.K.; Gjoønnes, J.; Hansen, V.; Li, X.Z.; Knutson-Wedel, M.; Waterloo, G.; Schryvers, D.; Wallenberg, L.R. GP-zones in Al-Zn-Mg alloys and their role in artificial aging. Acta Mater. 2001, 49, 3443-3451.

42. Bendo, A.; ,Matsuda, K.; Nishimura, K.; Nunomura, N.; Tsuchiya, T.; Lee, S.; Marioara, C.D.; Tsuru, T.; Yamaguchi, M.; Shimizu, K.; Toda, H. The possible transition mechanism for the meta-stable phase in the 7xxx aluminium. Mater Sci Tech-Lond 2020, 36, 1621-1627.

43. Chen, Y.X. Microstructure and texture in the surface gradient nanostructured nickle and aluminum alloys. Doctor's Thesis, Northwestern Polytechnical University, Xian, China, 2018.

44. Li, W.W.; Zuo, X.Q.; Liu, Z.Y.; Hu, S. Microstructure characteristics and research progress of high strength and high toughness aluminum alloy. Hot Work. Technol. 2015, 44, 12-15.

45. Wang, Y.C.; Tong, X.; You, G.Q.; Cao, L.F. Research progress and prospects of the microstructures, properties, and forming techniques of Al-Li Alloy. Rare Metal Mat Eng. 2021, 50, 1069-1083.

46. Cui, Z.Q.; Tan, Y.C.; Metallography and Heat Treatment, 2nd ed.; Machinery Industry Press: Beijing, China, 2008; PP.176-178.

47. Shu, W.X. Solidification characteristics and strengthening-thoughening mechanisms of $7 \mathrm{xxx}$ al alloys with tailored $\mathrm{Mg}$ and $\mathrm{Cu}$ elements. Doctor's Thesis. University of Science and Technology Beijing, Beijing, China. 2015.

48. Dai, X.Y.; Xia, C.Q.; Liu, C.B.; Gu, Y. Effects of solution treatment and aging process on microstructure and mechanical properties of 7xxx aluminium alloy. T Mater Heat Treat. 2007, 04, 59-63.

49. Yu, H.Q. Principle of metal plastic forming, 1st ed.; Machinery Industry Press: Beijing, China, 2018; PP.12-13.

50. Huang, K.F.; Qin, Z.; Zhou, W.B.; Ren, Y.L.; Huang, L.; Xiang, J.; Tang, H.Q.; Zhu, Y.T.; Wei, Y.Z. Enhancement of strength mechanical and corrosion resistance of 7055 alloy with minor Sc and Y addition. Mater Res Express. 2021, 8, 016524.

51. Yan, Y.C.; Huang, B.; Li, W.J.; Qing, P.L.; He, B. Research progress of Al-Zn-Mg-Cu Ultra-high Strength aluminum alloy. Mater Rev. 2018, 32, 358-364.

52. Zhang, X.G.; Mei, F.Q.; Zhang, H.Y.; Wang, S.H.; Fang, C.F.; Hao, H. Effects of Gd and Y additions on microstructure and properties of Al-Zn-Mg-Cu-Zr alloys. Mater Sci Eng A. 2012, 552, 230-235.

53. Huang, L.P.; Chen, K.H.; Li, S. Influence of grain-boundary pre-precipitation and corrosion characteristics of inter-granular phases on corrosion behaviors of an Al-Zn-Mg-Cu alloy. Mater Sci Eng B. 2012, 177, 862-868.

54. Guan, R.G.; Tie, D. A Review on Grain Refinement of Aluminum Alloys: Progresses, Challenges and Prospects. Acta Metall Sin-Engl, 2017, 30, 409-432.

55. Charit, I.; Mishra, R. Effect of friction stir processed microstructure on tensile properties of an Al-Zn-Mg-Sc alloy upon subsequent aging heat treatment. J Mater Sci Technol, 2018, 34, 214-218.

56. Garner, A.; Euesden, R.; Yao, Y.; Aboura, Y.; Zhao, H.; Donoghue, J.; Curioni, M.; Gault, B.; Shanthraj, P.; Barrett, Z.; Engel, C.; Burnett, T.L.; Prangnell, P.B. Multiscale analysis of grain boundary microstructure in high strength 7xxx Al alloys. Acta Mater. 2021, 202, 190-210.

57. Menzemer, C.C.; Lam, D.F.; Srivatsan, T.S.; An investigation of strain concentration in high-strength $\mathrm{Al}-\mathrm{Zn}-\mathrm{Mg}-\mathrm{Cu}$ alloy 7085 subjected to tensile deformation. J Mater EngG Perform. 2021, 202, 190-210. 
58. Deschamps, A.; Hutchinson, C.R. Precipitation kinetics in metallic alloys: Experiments and modeling. Acta Mater. 2021, 220, 117338.

59. Liu, X.M.; Wang, Qian.; Zhao, Chuan.; Li, H.P.; Wang, M.L.; Chen, Dong.; Wang, H.W. Formation of ordered precipitates in Al-Sc-Er-(Si/Zr) alloy from first-principles study. J Rare Earth. 2021, 39, 609-620.

60. Chen, D.; Xia, C.J.; Liu, X.M.; Wu, Y.; Wang, M.L. The effect of alloying elements on the structural stability, and mechanical and electronic properties of Al3Sc: A first-principles study. Materials. 2019, 12, 1539.

61. Sun, S.P.; Li, X.P.; Lei, W.N.; Wang, H.J.; Wang, X.C.; J, H.F.; L, R.X.; J, Y.; Y, D.Q. Calculation of point defect structures and bonding behavior of $\mathrm{L1}_{2}-\mathrm{Al}_{3} \mathrm{Sc}$ intermetallic based on first-principles. Chin J Nonferrous Met. 2013, 23, $2147-2155$.

62. Peng, G. S.; Gu, Y.C.; Chen, S.Y.; Chen, K.H.; Fang, H.C.; Song, G.S. Research progress of relationship between multi-scale second phase particles and properties of Al-Zn-Mg-Cu alloys. Rare Metal Mat Eng. 2021, 50, 775-786.

63. Deng, Y.L.; Zhang, X.M. Development of aluminium and aluminium alloy. Chin J Nonferrous Met. 2019, $29,2115-2141$.

64. Rometsch. P.A.; Zhang, Y.; Knight, S. Heat treatment of 7xxx series aluminium alloys-Some recent developments. T Nonferr Metal Soc. 2014, 24, 2003-2017.

65. Ye, Z.Y. Corrosion behavior of new aluminum alloy and the effect of surface modification. Doctor's Thesi. Northwestern Polytechnical University, Xian, China. 2015.

66. Hu, H.Q. Principle of metal solidification. 2nd ed.; Machinery Industry Press: Beijing, China, 2000; PP.190-192.

67. Bai, Q.L.; Study on the cracking defects during direct-chill casting of 7xxx series aluminum alloys. Doctor's Thesis. University of Science and Technology Beijing, Beijing, China. 2016.

68. Guo, F.B.; Zhu, B.H.; Jin, L.B.; Wang, G.J.; Yan, H.W.; Li, Z.H.; Zhang, Y.A.; Xiong, B.Q. Microstructure and mechanical properties of 7A56 aluminum alloy after solution treatment. Rare Metals. 2021, 40, 168-175.

69. Zhang, J.L.; Song, B.; Wei, Q.S.; Bourell, D.; Shi, Y.S. A review of selective laser melting of aluminum alloys: Processing,microstructure, property and developing trends. J Mater Sci Technol. 2019, 35, 270-284.

70. Wang, T.; Yin, Z.M.; Sun, Qiang. Effect of homogenization treatment on microstructure and hot workability of high strength 7B04 aluminium alloy. Chin J Nonferrous Met. 2007, 02,335-339.

71. Liu, C.Y.; Teng, G.B.; Ma, Z.Y.; Wei, L.L.; Zhang, B.; Chen, Y. Effects of Sc and Zr microalloying on the microstructure and mechanical properties of high Cu content 7xxx Al alloy. Int J Min Met Mater. 2019, 26, 1559-1569.

72. Jia, M.; Zheng, Z.Q.; Gong, Z. Microstructure evolution of the 1469 Al-Cu-Li-Sc alloy during homogenization. J Alloy Compd. 2014, 614, 131-139.

73. Gazizov, M.; Teleshov, V.; Zakharov, V.; Kaibyshev, R. Solidification behaviour and the effects of homogenisation on the structure of an Al-Cu-Mg-Ag-Sc alloy. J Alloy Compd. 2011, 509, 9497-9507.

74. Xu, F.S.; Zhang, J.; Deng, Y.L.; Zhang, X.M. Effect of snake rolling on strength, toughness and microstructure of Al-Cu-Mg alloy plate. Chin J Nonferrous Met. 2017, 27, 2005-2011.

75. Xia, W.J. Researeh on special rolling techniques of wrought magnesium alloy sheet. Doctor's Thesis. Hunan University, Hunan, China. 2010.

76. Li, S.Y.; Q, N.; L, J.; Z, X.M. Microstructure, texture and mechanical properties of AA1060 aluminum plate processed by snake rolling. Mater Design. 2016, 90, 1010-1017.

77. Zhang, T.; Wu, Y.X.; Gong, H.; Zheng, X.Z.; Jiang, S.S. Effects of rolling parameters of snake hot rolling on strain distribution of aluminum alloy 7075. T Nonferr Metal Soc. 2014, 24, 2150-2156.

78. Qin, G.H.; Yang, Y.; Li, Q.; Lin, F. Analysis and prediction of muti-pass snake hot rolling for 7075 aluminum alloy thick plate. Optics Precis Eng. 2017, 25, 437-446.

79. Song, M.; Liu, X.H.; Liu, X.; Liu, L.Z. Ultrafine microstructure and texture evolution of aluminum foil by asymmetric rolling. J Ccent South Univ. 2017, 24, 2783-2792.

80. Liang, S.B. Extrusion and heat treatment of aluminum alloy. 1st ed.; Central South University Press: Changsha, China, 2015; PP.470-472.

81. Feng, D.; Liu, S.D.; Han,N.M.; Chen, H.M.; Cao, W.K.; Han, Z.J. Multifactorial effects on microstructure, properties and through-thickness inhomogeneity of 7A55-RRA treated aluminum alloy thick plate. Chin J Nonferrous Met. 2019, 29, $1150-1160$.

82. Wang, J.Y. The mechanism research of strength, thoughness and aging stability of AA7021 aluminum alloy thin plates. Doctor's Thesis. University of Science and Technology Beijing, Beijing, China. 2019.

83. Wang, F.F.; Meng, W.; Zhang, H.W.; Han, Z.Q. Effects of under-ageing treatment on microstructure and mechanical properties of squeeze-cast Al-Zn-Mg-Cu alloy. T Nonferr Metal Soc. 2018, 28, 1920-1927.

84. Wang, X.G.; Ma, L.Y.; Microstructure and property Evolution of Al-Zn-Mg-Cu alloy with Ho addition during homogenization. Rare Metal Mat Eng. 2021, 50, 2771-2776.

85. Zhang, K.R.; Xu, X.J.; Zhang, J. Effect of multistage solution and aging treatment on microstructure and properties of 7xxx series ultra-high strength cold extruded aluminum alloy. Heat Treat Metal. 2021, 46, 165-168.

86. Zhang, C.S.; Zhang, Z.G.; Liu, M.P.; Bao, E.C.; Chen, L.; Zhao, G.Q. Effects of single- and multi-stage solid solution treatments on microstructure and properties of as-extruded AA7055 helical profile. T Nonferr Metal Soc. 2021, 31, $1885-1901$.

87. Liu, P.; Hu, L.L.; Zhang, Q.H.; Yang, C.P.; Yu, Z.S.; Zhang, J.Q.; Hu, J.M.; Cao, F.H. Effect of aging treatment on microstructure and corrosion behavior of Al-Zn-Mg aluminum alloy in aqueous solutions with different aggressiveions. J Mater Sci Technol. 2021, 64, 85-98.

88. Q, M.; Tang, J.G.; Ye, L.Y.; Li, C.B.; Li, J.X.; Zhou, W.; Deng, Y.L. Comparative study on the effect of over-aging and addition of Zr on the corrosion resistance of Al-Zn-Mg alloy. Mater Rev. 2020, 34, 2083-2087. 
89. Zheng, X.; Tang, J.G.; Zhang, Y.; Chen, M.Y.; Liu, S.D.; Zhu, Y.T.; He, K.H.; Zhang, X.M. Effect of interrupt aging on the mechanical properties and the local corrosion resistance of $\mathrm{Al}-\mathrm{Zn}-\mathrm{Mg}-\mathrm{Cu}$ alloy thick plate. Chin J Nonferrous Met. http://kns.cnki.net/kcms/detail/43.1238.tg.20211022.1156.003.html.

90. Ding, Q.W. Microstructure and properties of age-hardenable Al-Mg-Zn aluminum alloy and the process optimization. Doctor's Thesis. University of Science and Technology Beijing, Beijing, China. 2019.

91. Gokhan, O.; Ahmet, K. Properties of AA7075 aluminum alloy in aging and retrogression and reaging process. T Nonferr Metal Soc. 2017, 27, 2357-2362.

92. Liao, B. Basic Research on deformation behavior and heat treatment characteristics of 7055 aluminum alloy thick plate. Doctor's Thesis. Chongqing University, Chongqing, China. 2019.

93. Jaburek, N.; Merklein, M. Influence of a retrogression and reaging (RRA)-treatment on the mechanical and microstructural characteristics of the aluminium alloy AlZn4.5Mg1. Prod Eng Res Devel. 2015, 09, 161-166. 